\title{
THE ECOLOGICAL AND PHYSIOLOGICAL CONTROL OF WATER LOSS IN SNAKES
}

By

THOMAS HENRY KRAKAUER

A DISSERTATION PRESENTED TO THE GRADUATE COUNCIL OP

THE UNIVERSITY OF FLORIDA

IN PARTIAL FULFILLMENT OF THE REQUIREMENTS FOR THB DEGREE OF DOCTOR OF PHILOSOPHY

UNIVERSITY OF FLORIDA

1970 



\section{ACKNOWLEDGEMENTS}

I would like to thank Drs. Brian K. McNab, Frank G. Nordlie and Daniel A. Belkin for help during the course of the study and during the preparation of this manuscript. Dr. John F. Anderson and Mr. Paul E. Moler helped in many ways including serving as valuable sounding boards for some of my ideas. My wife, Janet, helped in all the ways that wives usually do, and helped in the preparation of the illustrations. 


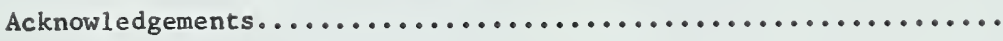

List of Tables................................... iv

List of Figures................................ v v

Abstract....................................... vii

Introduction.................................... I

Materials and Methods............................... 3

Skin Permeability in Air.......................... 3

Skin Perneability in Aqueous Media................... 7

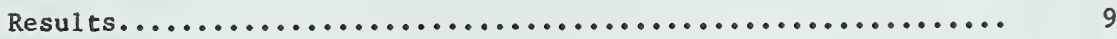

Discussion..................................... 28

Cutaneous Water Loss............................ 28

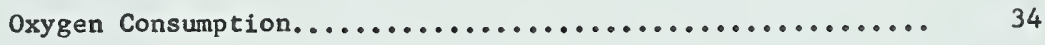

Respiratory Water Loss.......................... 34

Partitioning of Water Loss...................... 38

Water Exchange with Aqueous Media................... 45

Conclusions.................................... 50

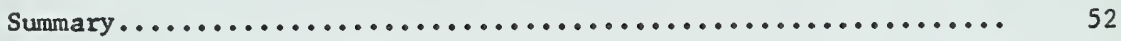

References...................................... 54

Biographical sketch............................. 57 


\section{LIST OF TABLES}

Table 1 Cutaneous water loss........................ 24

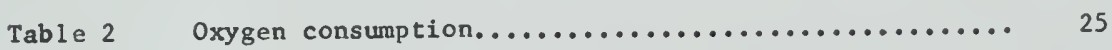

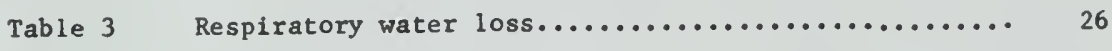

Table 4 Percent of total water loss that is cutaneous....... 27 
LIST OF FIGURES

Figure 1 Diagram of equipment.......................

Figure 2 Cutaneous water loss as a function of weight

in Natrix fasciata pictiventris.

Figure 3 Cutaneous water loss as a function of weight

in Natrix fasciata compressicauda.

Figure 4 Cutaneous water loss as a function of weight

at $25^{\circ} \mathrm{C}$.

Figure 5 Oxygen consumption as a function of weight

in Natrix fasciata pictiventris.

Figure 6 0xygen consumption as a function of weight

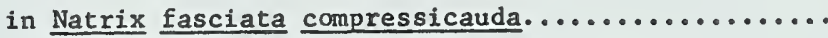

Figure 7 Oxygen consumption as a function of weight at $25^{\circ} \mathrm{C}$.

Figure 8 Respiratory water loss as a function of weight

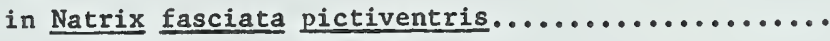

Figure 9 Respiratory water loss as a function of weight

in Natrix fasciata compressicauda.

Figure 10 Respiratory water loss as a function of weight

at $25^{\circ} \mathrm{C}$.

Figure 11 Isotope flux rates as a function of weight

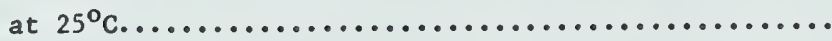

Figure 12 The effects of body position and activity on

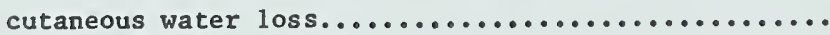


Figure 13 Respiratory water loss per milliliter of oxygen consumed as a function of oxygen consumption in Natrix fasciata pictiventris and Thamnophis

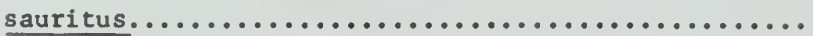

Figure 14 Respiratory water loss per milliliter of oxygen consumed as a function of oxygen consumption in Natrix fasciata compressicauda, Natrix cyclopion

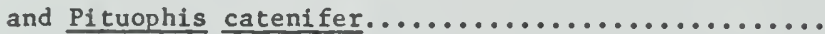

Figure 15 Minute volume as a function of oxygen consumption in Natrix fasciata pictiventris and Thamnophis sauritus................................ 40

Figure 16 Minute volume as a function of oxygen consumption in Natrix fasciata compressicauda............. 40

Figure 17 The fraction of oxygen in the expired air as

a function of oxygen consumption in Natrix

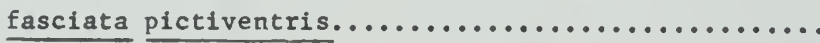

Figure 18 The fraction of oxygen in the expired air as

a function of oxygen consumption in Natrix fasciata compressicauda.

Figure 19 The fraction of oxygen in the expired air as a function of oxygen consumption in Thamnophis sauritus 
Abstract of Dissertation Presented to the Graduate Council

of the University of Florida in Partial Fulfillment of the Requirements for the Degree of Doctor of Philosophy

THE ECOLOGICAL AND PHYSIOLOGICAL CONTROL OF WATER LOSS IN SNAKES

By

Thomas Henry Krakauer

August, 1970

Chairman: Brian K. McNab

Major Department: Zoology

The cutaneous and respiratory water loss of Natrix fasciata pictiventris, N. 五. compressicauda and Thamnophis sauritus were measured using a flowing air system and a dew-point hygrometer. Cutaneous water loss, when expressed as a function of the vapor pressure deficit, did not change with temperature. Cutaneous water loss was almost three times greater in N. $\underline{\text {. pictiventris }}$ (fresh water) than in N. $\underline{\text {. }}$ compressicauda (salt water) and amounted to 92 and 80 per cent $\left(25^{\circ} \mathrm{C}\right)$ of the total water loss respectively.

Determinations of skin permeability in aqueous media by in vivo measurements of tritiated water flux indicate that external salinity has no effect on the efflux from the animal. The skin permeability of $\underline{N}$. $\underline{f}$. pictiventris in water is greater than that of $\underline{N}$. $\underline{\text {. }}$. compressicauda. 
No differences, between subspecies, in respiratory water loss were found at 15,25 and $32^{\circ} \mathrm{C}$. Respiratory water loss of Thamnophis was lower, correlating with a lower level of oxygen consumption. A decrease in the amount of water lost per ml of oxygen consumed tended to keep the respiratory water loss constant with increased temperature (corrected for saturation deficit). Respiratory water loss increases less rapidly with activity than does oxygen consumption.

The rate of respiratory water loss is not modified, except by changes in oxygen consumption, while the cutaneous permeability is responsive to ecological demands. 


\section{INTRODUCTION}

Reptiles are able to remain in water balance under a wide range of environmental conditions. Marine and terrestrial species live in dehydrating media, while fresh-water reptiles are exposed to an environment that favors the entry of water into the animal. Water loss takes place at three sites: cloaca, respiratory tract, and skin. This study deals with the cutaneous and respiratory components.

Classically, reptiles were viewed to have an impermeable integument, with the respiratory tract stated to be the route of most of the water 1oss (Chew, 1961; Pettus, 1958). Recent studies, however, indicate that rates of water loss of reptiles vary from those typical of "waterproof" insects to those of amphibians (see Schmidt-Nielsen, 1969; Krakauer et al., 1968), and that the major component of water loss is cutaneous (Bentley and Schmidt-Nielsen, 1966; Schmidt-Nielsen and Bentley, 1966; Clausen, 1967; Dawson et al., 1966; Prange and Schmidt-Nielsen; 1969). The rates of water loss correlate with habitat aridity (Bogert and Cowles, 1947; see also Krakauer et al., 1968; Gans et al., 1968).

In this study I will examine the water loss of three closely related, but ecologically distinct, snakes: a brackish-water snake, the mangrove water snake (Natrix fasciata compressicauda); a fresh-water snake, the Florida banded water snake (N. $\underline{\underline{f}}$ pictiventris); and a more 
terrestrial snake, the ribbon snake (Thamnophis sauritus). The Natrix and Thamnophis live near water but differ in the amount of time spent in water. The desert gopher snake (Pituophis catenifer) and the green water snake (Natrix cyclopion) were also studied. The variability of water loss is examined to determine how the rate of water loss can be modified. Data are presented on the changes in cutaneous and respiratory water loss with changes in ecology, body weight, temperature, activity, shedding cycle, and external medium (dry air, distilled water, and sea water). 


\section{MATERIALS AND METHODS}

Natrix fasciata pictiventris, N. cyclopion, and $\underline{\text { N. sauritus }}$ were collected at several localities in Alachua County, Florida. The specimen of $\underline{P}$. catenifer was obtained without data from an animal dealer in southern California. N. ‥ compressicauda were collected at Matheson Hammock, Dade County, Florida and in Monroe County, 35 miles southwest of Homestead, Dade County, Florida. These sites were pioneer and secondary mangrove association with salinity that varied with rainfall (14-41 parts per thousand; Tabb et al., 1962).

The Natrix and Thamnophis were maintained in the 1aboratory on a diet of fish in dry cages, and held at $25 \pm 1^{\circ} \mathrm{C}$ with 12 hours of light daily. Tap water was provided. The Pituophis was kept under similar conditions except at fluctuating room temperature (ca. $\left.26^{\circ} \mathrm{C}\right)$. All water loss measurements were made on animals after they had fasted for at least one week and at known times during the shedding cycle.

Skin Permeability in Air

A flowing air desiccation system was used to determine water loss to dry air (Fig. 1). The respiratory and cutaneous water losses were measured separately. A partition between a head and body chamber was created by sliding the punctured tip of a tapered latex balloon (Trojan-enz No. 175) around the animal's neck, and the open end over a collar on the plexiglas head chamber ( $320 \mathrm{~m} 1)$. The snake's body was tied to a coarse mesh wire screen by a pipe 
苾㟧

年 


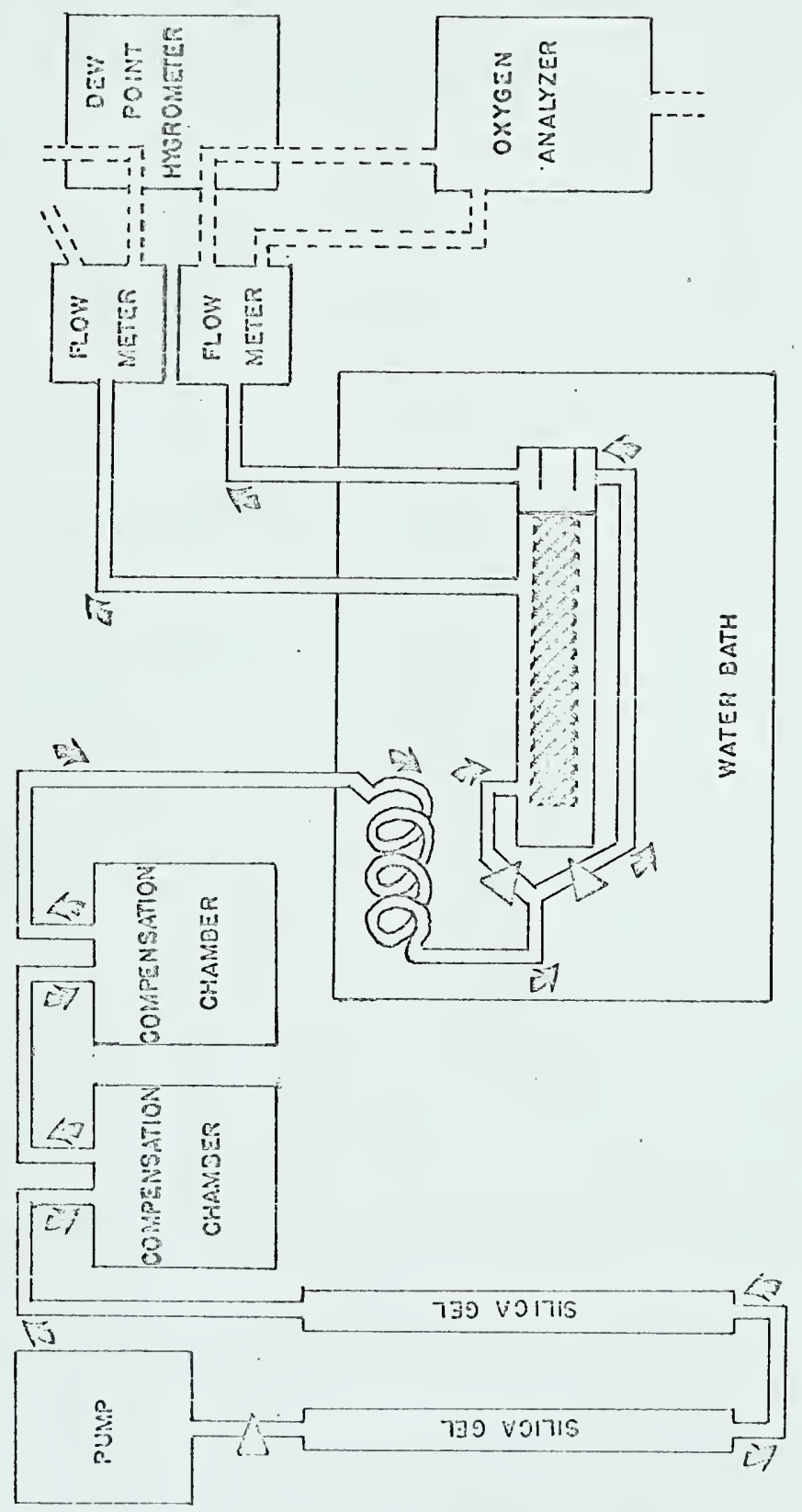


cleaner around the neck and inserted into one of two body chambers (2.5 or 3.0 liter glass cylinders; $7 \mathrm{~cm}$ diameter). The screen permitted air circulation around the animal. The head and body chambers were then clamped together and placed in a 2401 iter Forma water bath.

Measurements were made at 15,25 and $35^{\circ} \mathrm{C}$ over $3-10$-hour periods during daylight. If defecation or urination occurred, the measurements were discarded. The animals were weighed to the nearest $0.1 \mathrm{~g}$ before and after each experiment. A diaphragm pump maintained flow rates between 40 and $1,200 \mathrm{cc} / \mathrm{min}$ to keep the relative humidity in the chamber approximately between 10 and 30 per cent. Flow control was maintained upstream of the chamber to prevent a large pressure buildup in the chamber.

The airstream from the body chamber passed through a flowmeter and either to room air, or through a dew point hygrometer (Cambridge Systems Model 922-c1). The airstream from the head chamber passed through a flowmeter and either directly through silica gel and ascarite tubes (to remove water vapor and carbon dioxide) to a Beckman $\mathrm{F}_{3}$ Paramagnet1c oxygen analyzer, or through the hygrometer and then through the tubes to the oxygen analyzer. Reducing the oxygen concentration 1 per cent below ambient resulted in fullscale deflection of the chart recorder. Chart recorder output from both machines provided continuous measurements of $\mathrm{O}_{2}$ consumption and alternate measurements of water loss.

At the end of each experiment the animal was removed, the chamber resealed, and the background dew points determined at the experimental flow rates. Background dew points averaged -10.6 and 
$-20.1^{\circ} \mathrm{C}$ for the head and body chambers respectively. The higher water content of the head chamber resulted from the lower flow rates required to obtain sufficient scale deflection from the oxygen analyzer. Water loss was calculated by subtracting the background water loss ( $f$ low rate $x$ water content) from the experimental water loss (flow rate $\mathbf{x}$ water content). Rates of water loss calculated from the hygrometer were within 10 per cent of the rates calculated from weight change of a container of water placed in the system. The water loss data are presented as a function of the water vapor pressure deficit (mmH) to allow comparisons between values obtained at different temperatures and relative humidity. The oxygen consumption values were converted to values STPD.

\section{Skin Permeability in Aqueous Media}

To measure the unidirectional flow of water from the snakes to the aqueous media, snakes were injected intraperitoneally with sufficient tritiated water (THO) in saline (specific activity $100 \mathrm{uc} / \mathrm{ml}$ ) to obtain an internal concentration of $1=2 \mathrm{uc} / \mathrm{m} 1$ body water. The injected volume was less than 1 per cent of the estimated body water. The snakes were placed in the chamber described above, and left for one hour to allow the THO to become uniformly distributed in the animal's water space (see Gans et al., 1968). Then the body chamber was filled with 2.0 to 2.5 liters of either distilled water or filtered sea water (28-29 parts per thousand) and immersed in a water bath at $25^{\circ} \mathrm{C}$. A vibrator pump recirculated the fluid through the body chamber at a rate of $200 \mathrm{ml} / \mathrm{min}(40.6 \mathrm{~cm} / \mathrm{min})$. The snakes were exposed to each solution for at least four hours. Periodically $1 \mathrm{ml}$ aliquots were removed from the medium and counted in a liquid 
scintillation counter using Bray's solution as a scintillator. After at least 11 samples had been taken, the snake was removed from the chamber and $0.1 \mathrm{ml}$ of plasma obtained by cardiac puncture was prepared for counting. The plasma counts were corrected for quenching. Room air was pumped through the head chamber $(600 \mathrm{ml} / \mathrm{min})$ to glass tubes immersed in a 1-methoxy-2-propanol-dry ice bath to freeze dry the airstream.

The water efflux was calculated from the increase of THO in the external medium and from the plasma THO:

$$
\text { Flux }=(V \cdot \Delta C P M) /\left(P_{\bar{X}} \cdot t\right)
$$

where the flux is in milliliters per minute, $V$ is the volume in milliliters of the external compartment, $\triangle \mathrm{CPM}$ is the increase in THO in the medium during the sampling period, $P_{\bar{X}}$ is the mean THO count per ml of the body water space during the sampling period, and $t$ is the duration in minutes of the sampling period. The plasma counts corresponding to each sampling time were calculated by adding $\mathrm{V} \cdot \overline{\mathrm{CPM}} / 0.66 \mathrm{~W}$

to the final plasma counts; where $W$ equals body weight, and $\overline{C P M}$ is the mean THO activity during the sampling period $(0.66$ is an estimate of the per cent body water; Bentley, 1959). An alternative value of 0.73 for the per cent body water of fresh-water reptiles is presented by Thorson (1968). Flux values using this figure are less than 2 per cent greater than when 0.66 is used. The specific activity of the bath remained a small fraction of that in the animal $\left(10^{-3}\right)$, so backflux was neglected. Sharp breaks in the curves of CPM against time were taken to indicate urination and were excluded from the calculations of mean water loss. 


\section{RESULTS}

Figures 2-10 present resting values for cutaneous water loss, oxygen consumption and respiratory water loss. Cutaneous water loss is not affected by the shedding stage until the outer epidermal generation splits (see Gans et al., 1968). Logarithmic plots are employed because water loss and oxygen consumption are most simply expressed as power functions of body weight. Tables 1, 2 and 3 present the sample means and the regression equations calculated from the logarithmically transformed data by the method of least squares. The mean and standard error of the cutaneous fraction of total water loss are presented in Table 4 (only those pairs of water loss values with similar oxygen consumption were used). Regression analysis of these data indicates that this fraction remains constant with changing weight. There is no statistically significant difference between the THO efflux to fresh and salt water (Fig. 11), although the mean flux through the skin of both subspecies was higher to fresh water than to sea water.

Analysis of these data is left to the ensuing section. 
Fig. 2. Cutaneous water loss as a function of weight in Natrix fasciata pictiventris.

Fig. 3. Cutaneous water loss as a function of weight in Natrix fasciata compressicauda. 

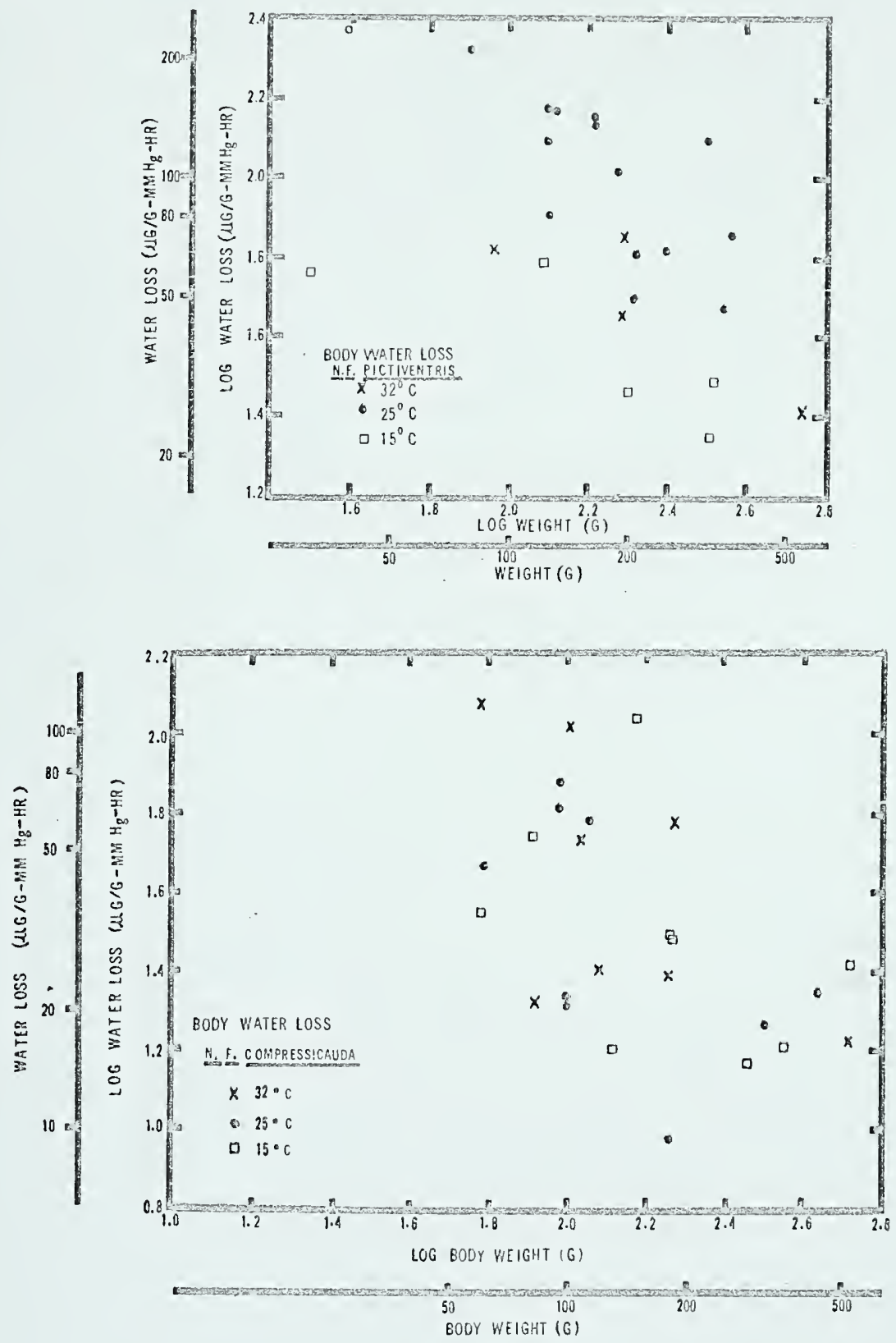
Fig. 4. Cutaneous water loss as a function of weight at
$25^{\circ} \mathrm{C}$. The solid square represents the rate of water
loss of a Thamnophis sauritus after a heavy feeding. 


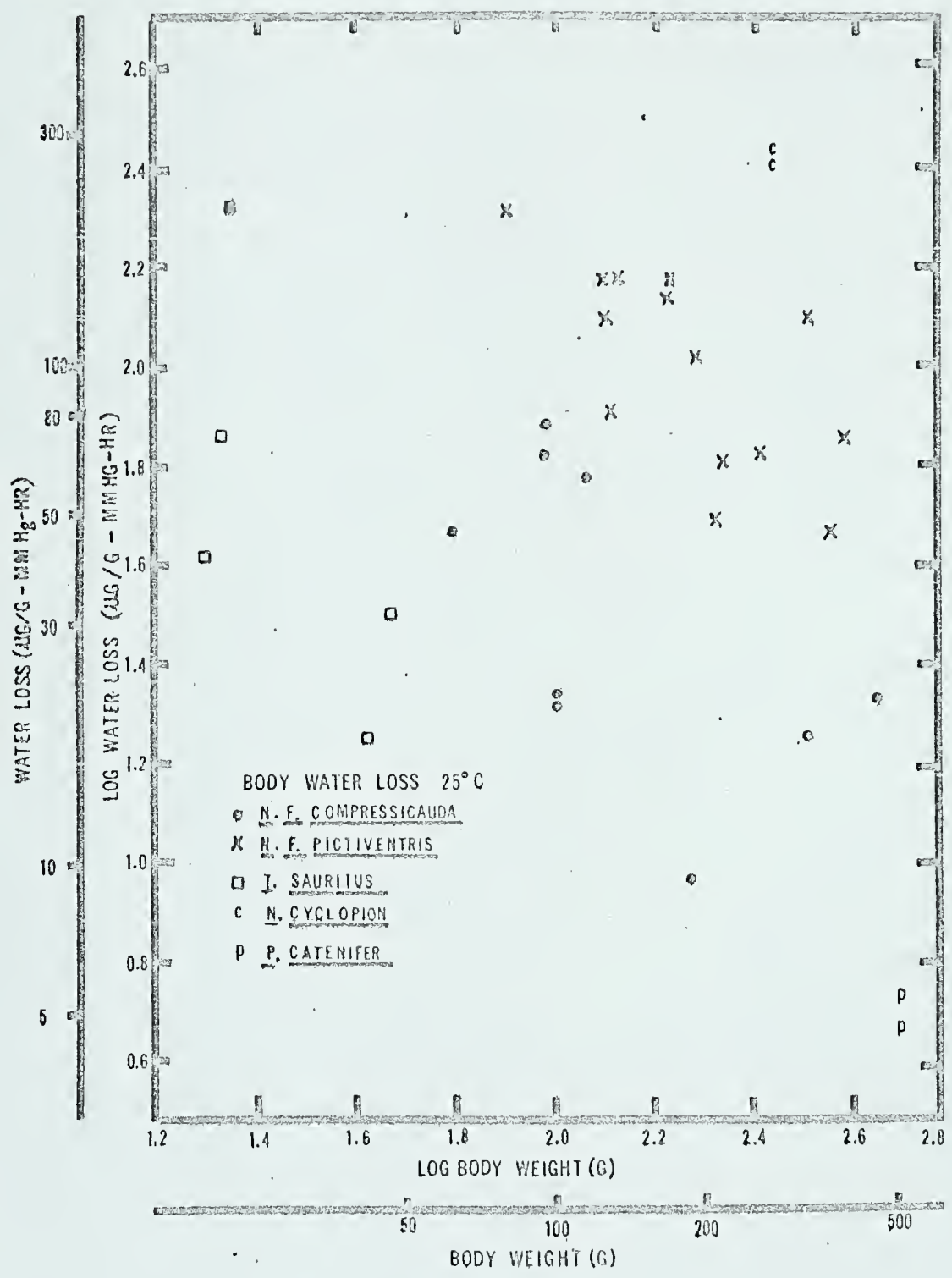


Fig. 5. Oxygen consumption as a function of weight in Natrix fasciata pictiventris.

Fig. 6. Oxygen consumption as a function of weight in Natrix fasciata compressicauda. 

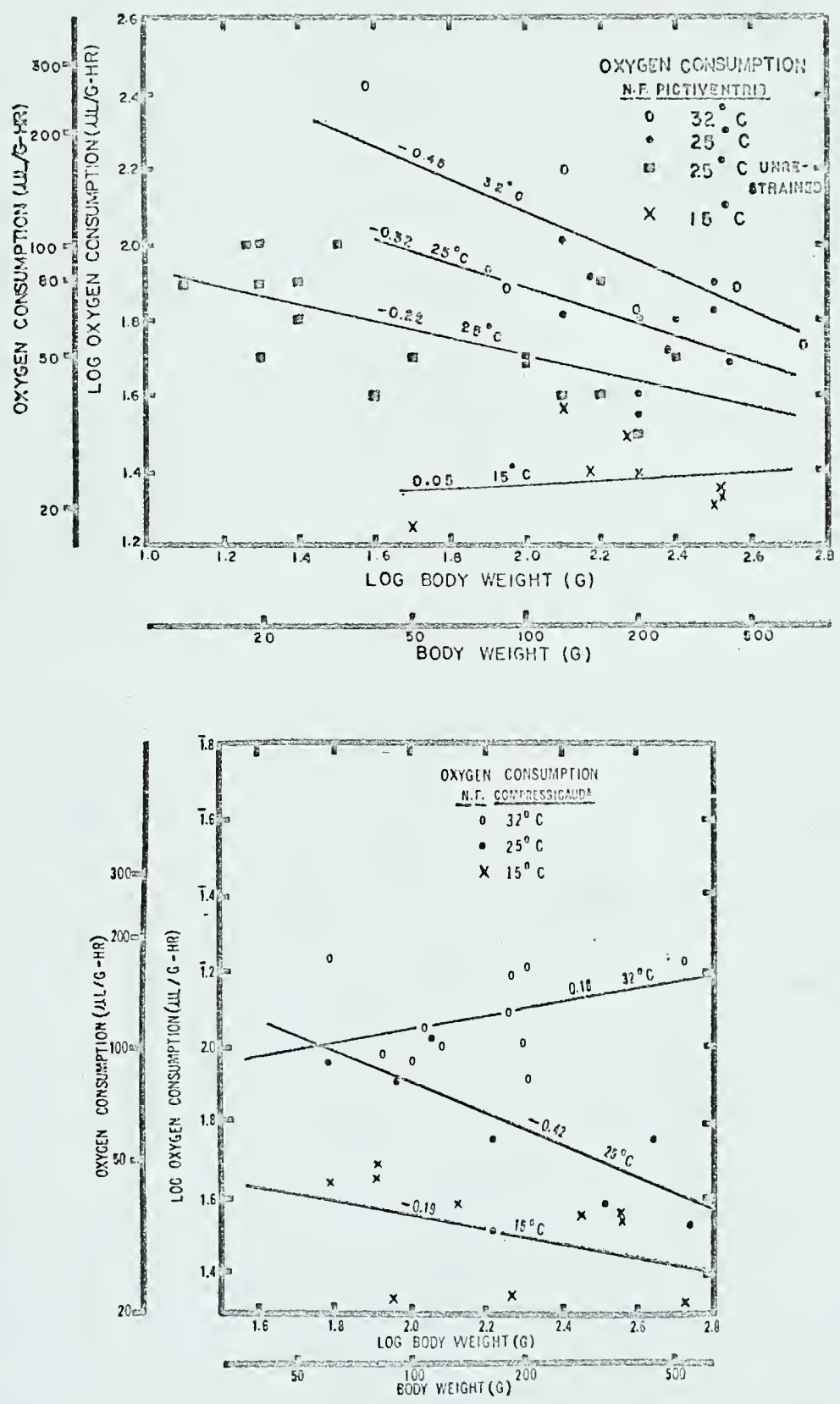


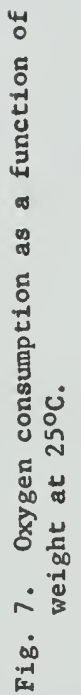




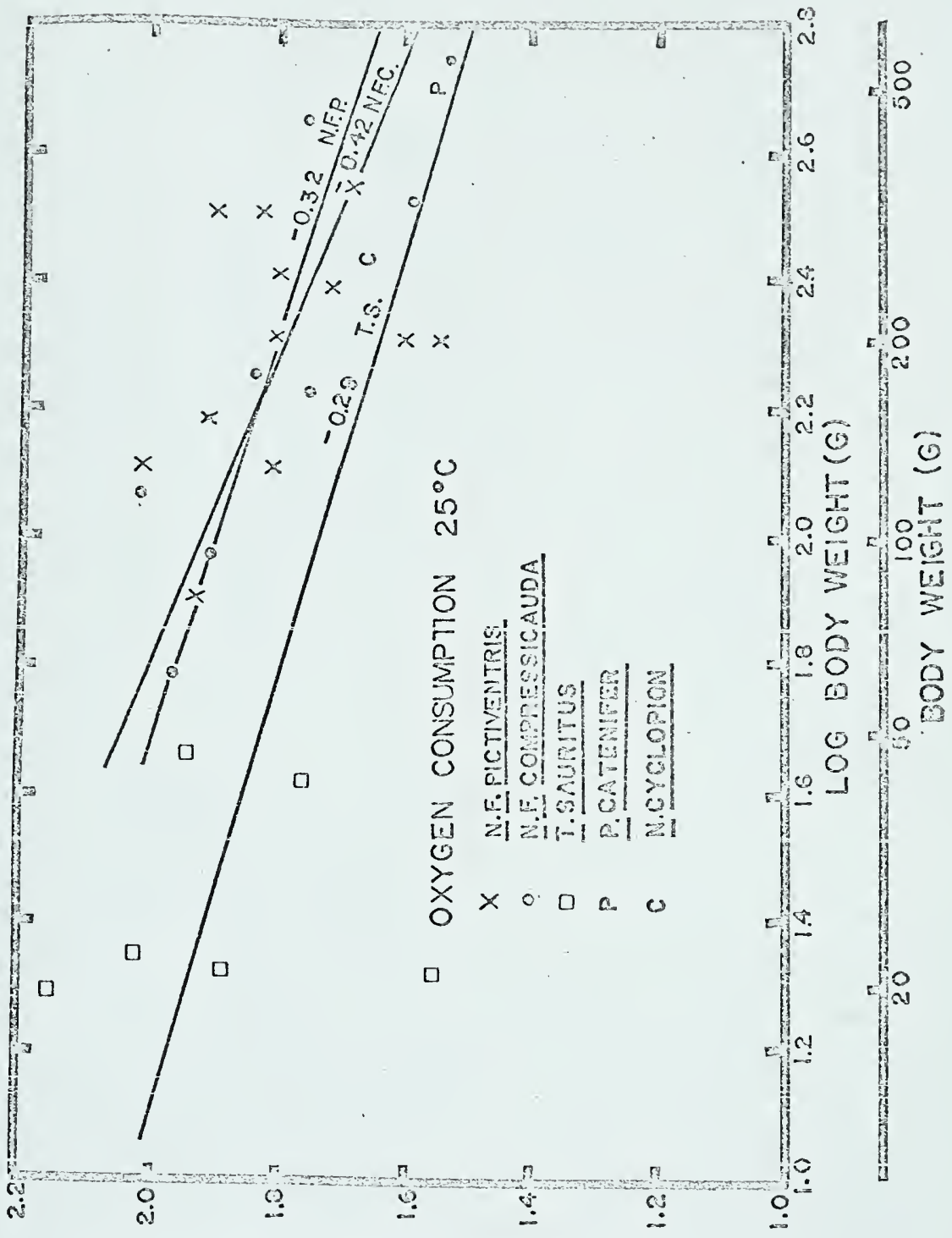

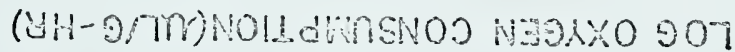

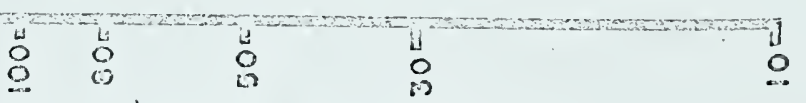

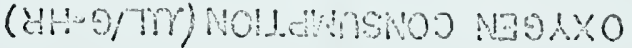


Fig. 8. Respiratory water loss as a function of weight in Natrix fasciata pictiventris.

Fig. 9. Respiratory water loss as a function of weight in Natrix fasciata compressicauda. 

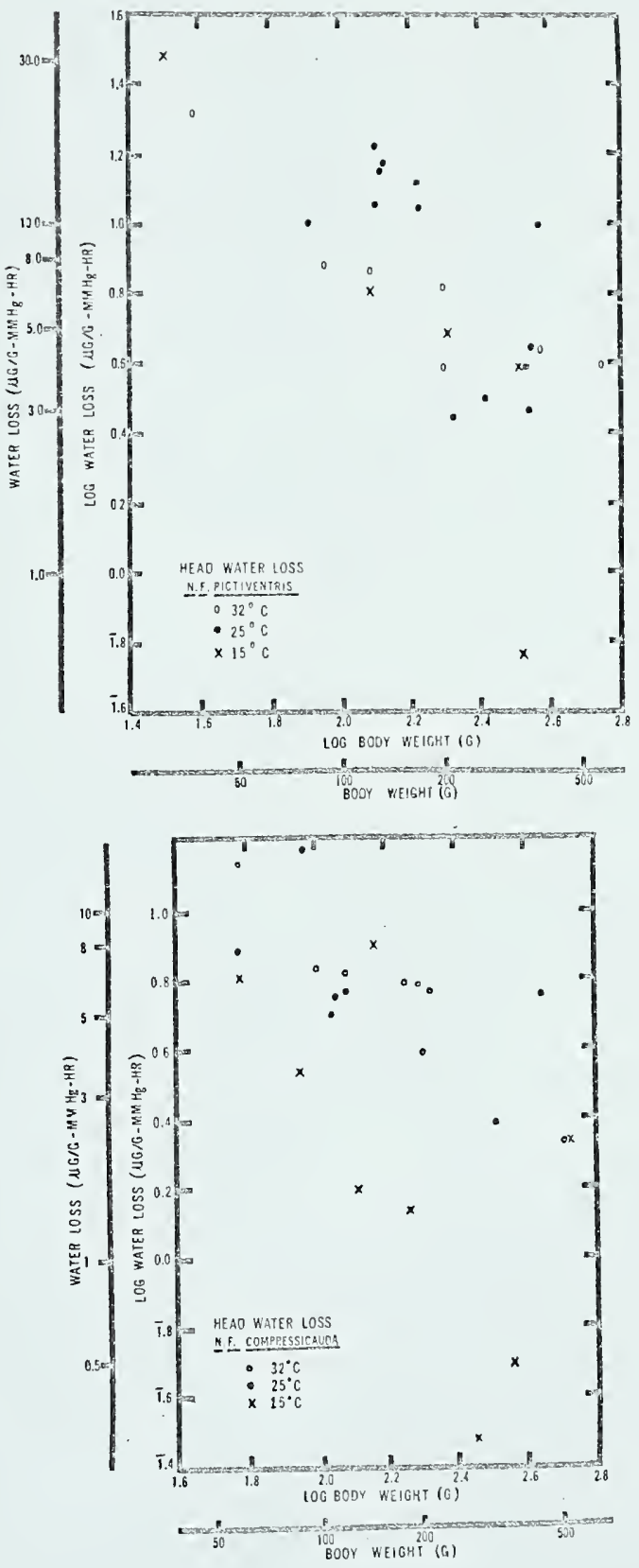


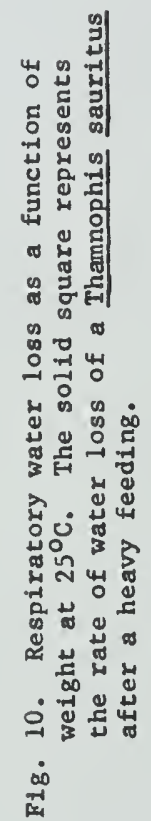




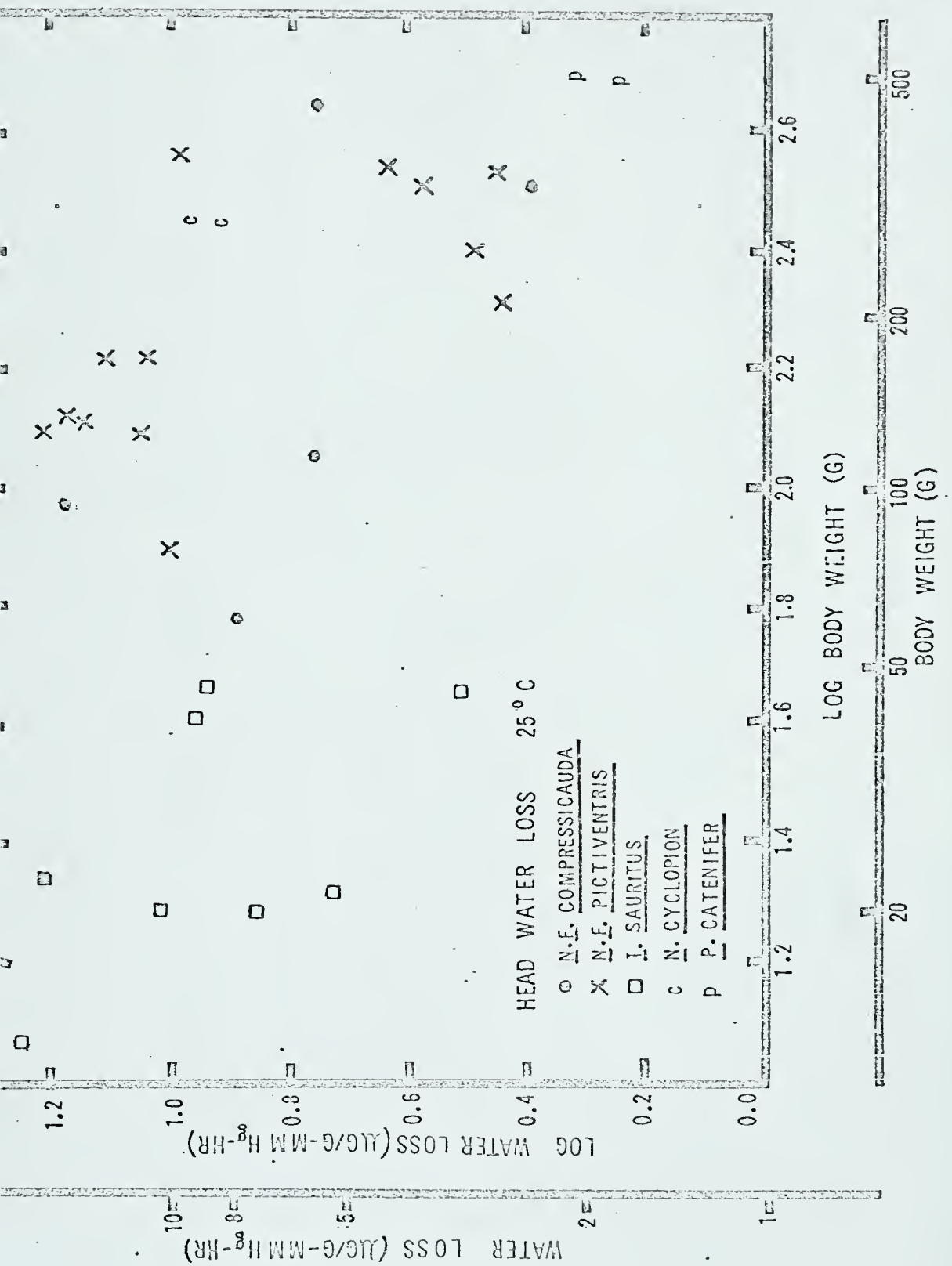


Fig. 11. Isotope flux rates as a function of weight at $25^{\circ} \mathrm{C}$. The mean rate of cutaneous water loss in dry air is included. 


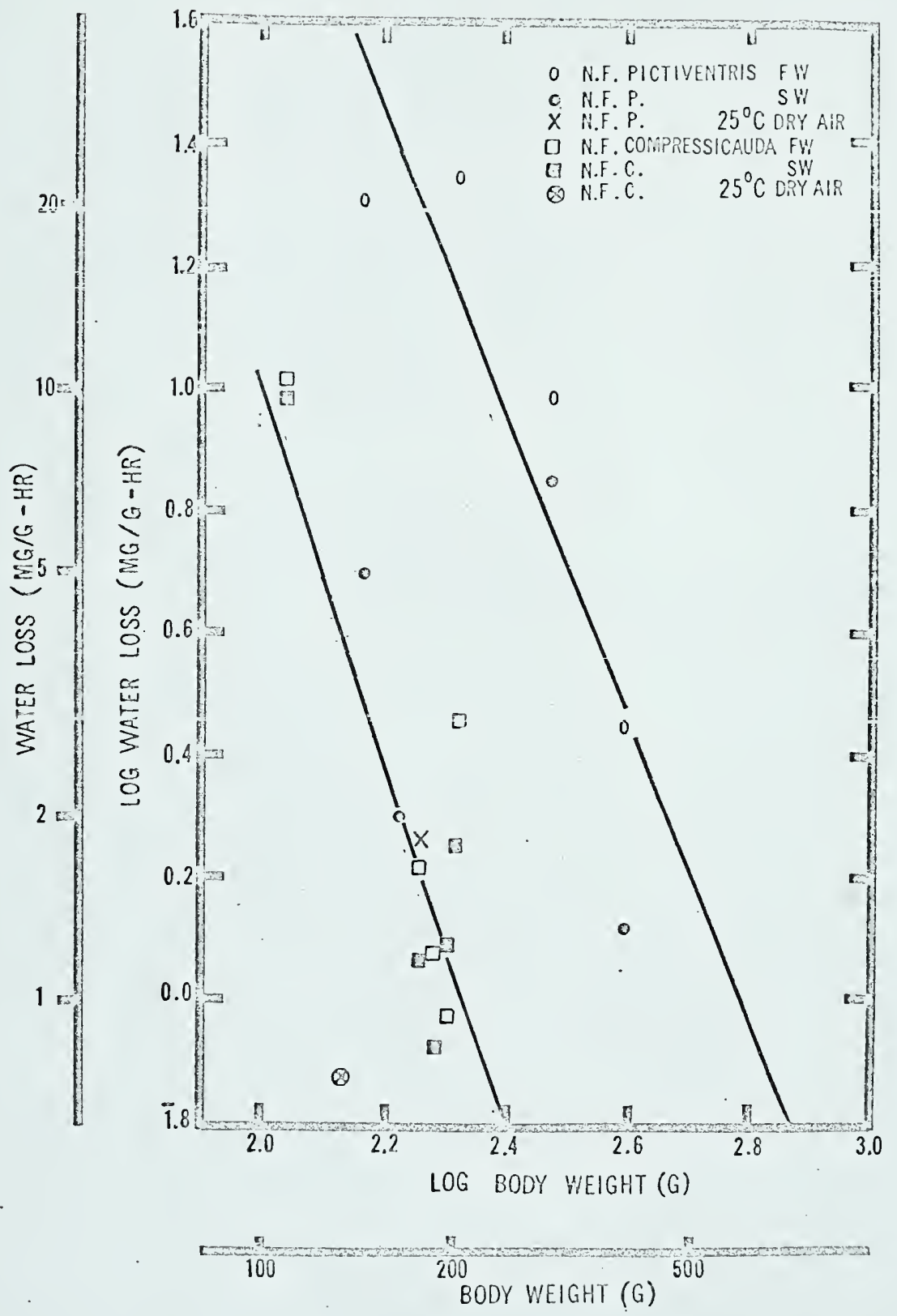




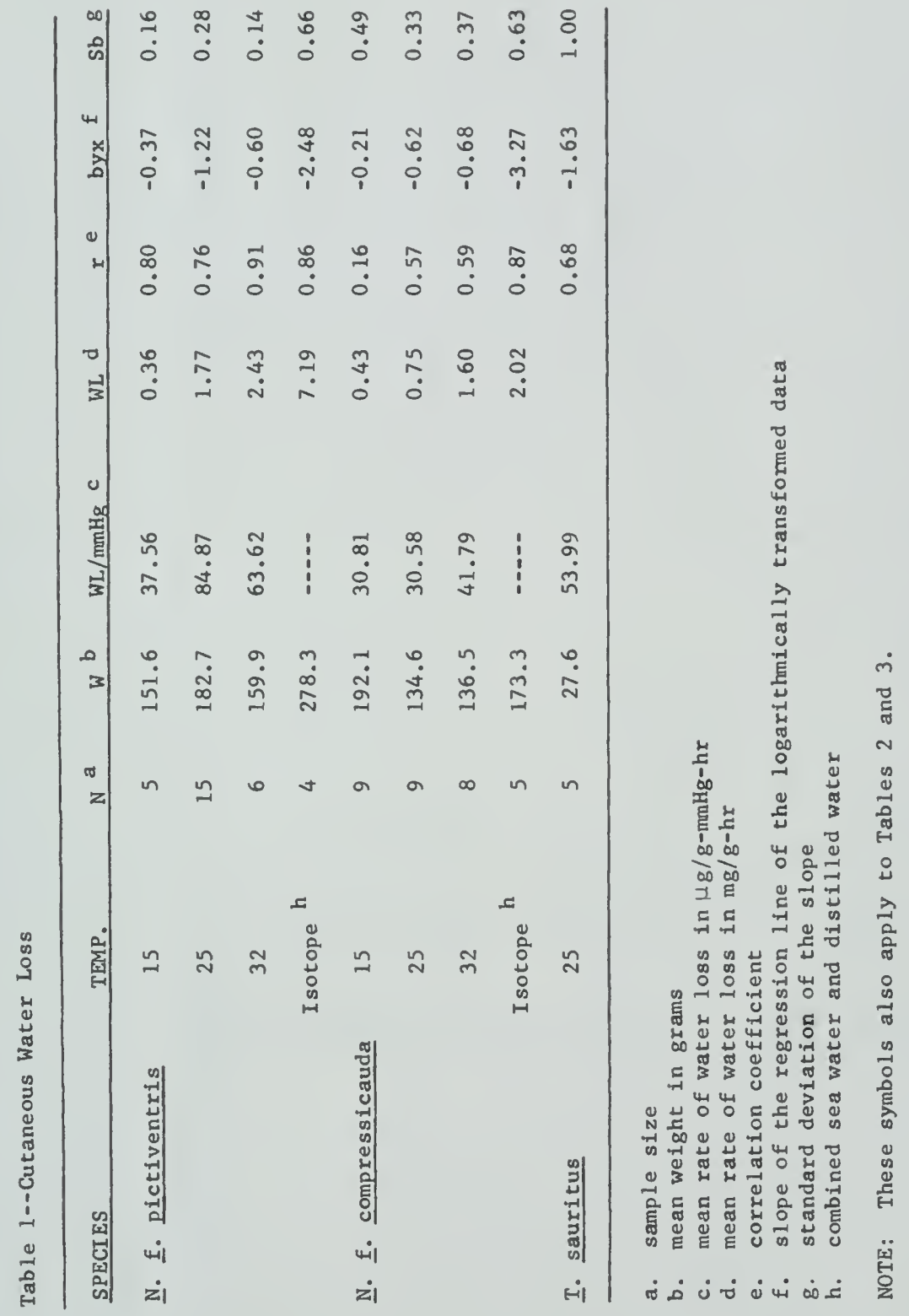




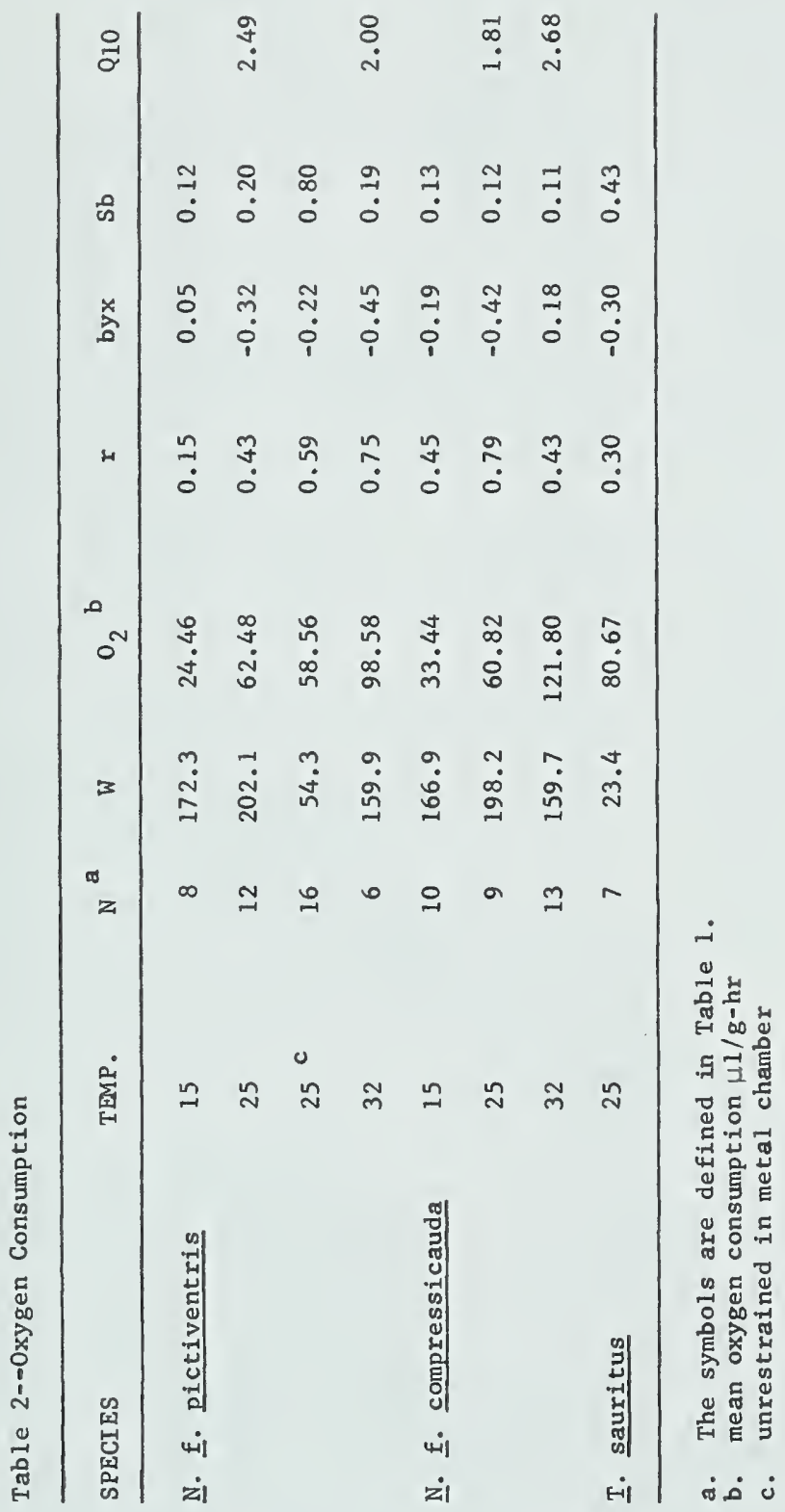




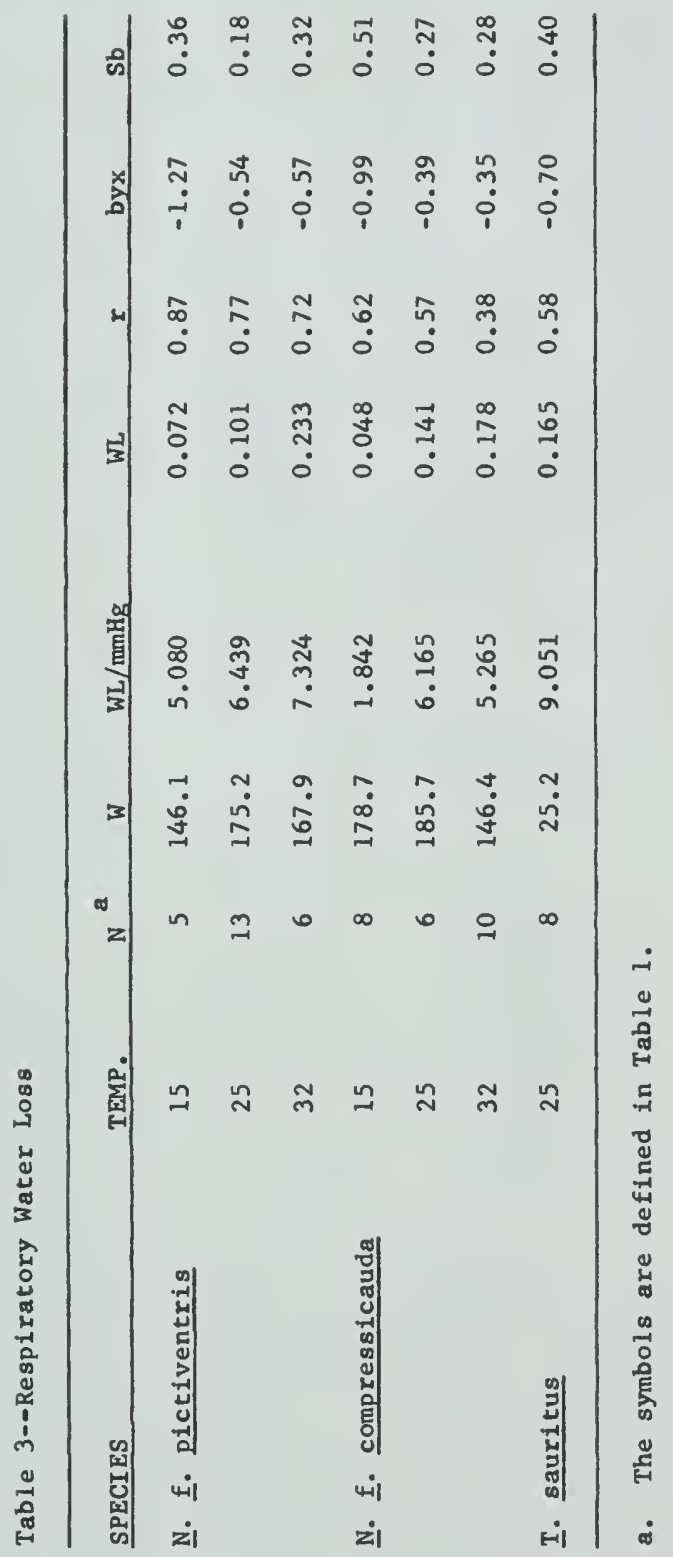




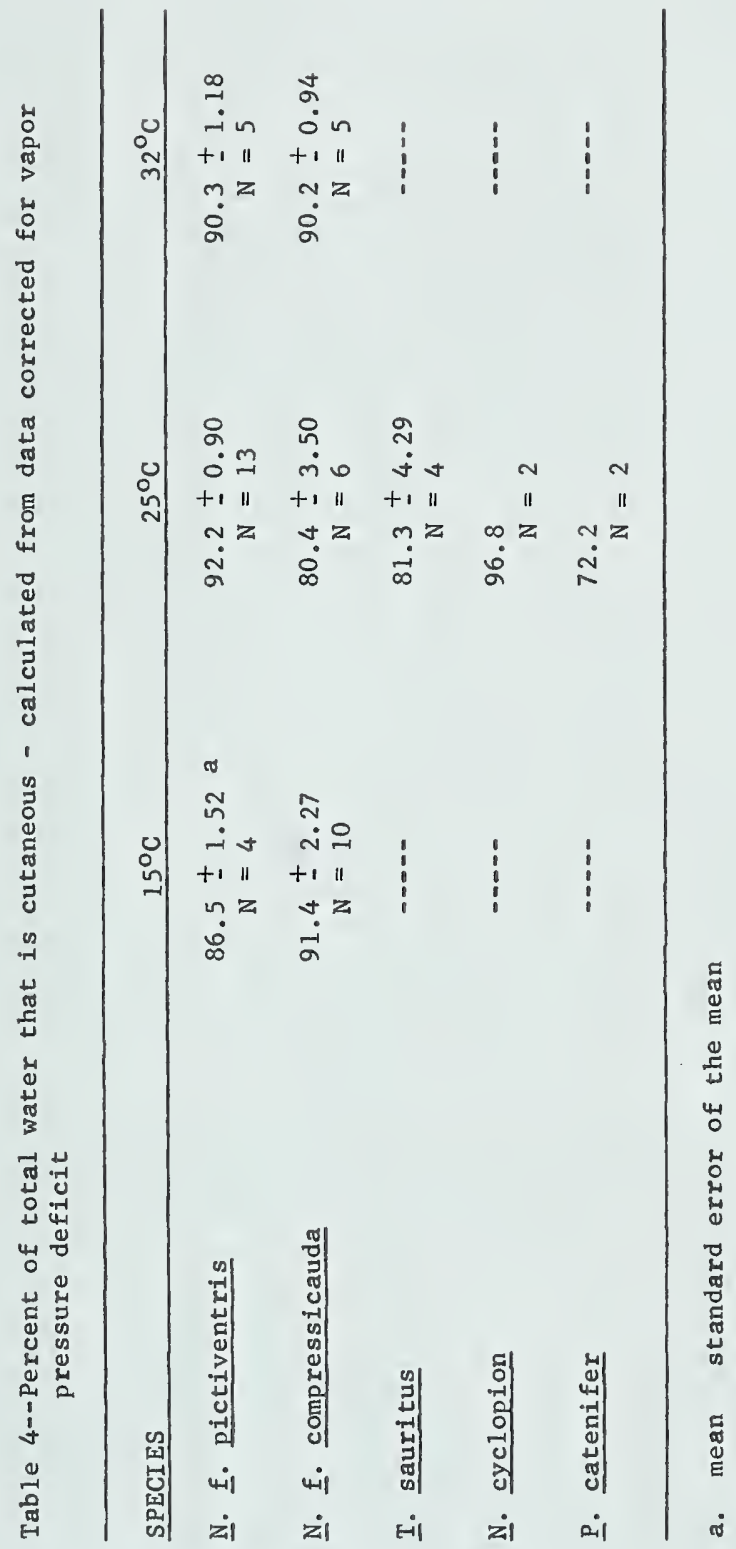


DISCUSSION

\section{Cutaneous Water Loss}

In snakes, the relationship of total water $10 s 8$ to body weight has been shown to be similar to that of surface area to body weight (Gans et al., 1968). It was hoped in this study to determine if this similarity reflected the importance of cutaneous water loss, or whether it resulted from a fortuitous combination of independent relationships of cutaneous and respiratory water loss to body weight. Table 4 indicates that in these snakes cutaneous water loss does predominate, but the variability of the data, probably enhanced by restraining the animals, prevents comparisons of water loss/body weight and surface area/body weight curves. The steepness of the water loss/body weight slopes probably reflects an increase in stockiness with an increase in weight, and change in the relative amount of the evaporative surface area (see below).

Any variation in the rates of water loss at a common weight cannot be due to differences in the drying power of the air, since water loss is expressed as a function of the vapor pressure deficit. Body temperature does not appear to have any clearcut effect on cutaneous water loss (Figs. 2, 3; Table 1). This indicates that an increase in metabolism and, presumably, a change in peripheral perfusion have no effect on the rate of water loss. One snake even continued to lose water at its normal resting rate after death. 
Other data, when recalculated to factor out saturation deficit, also indicate that no saturation deficit-independent increase in cutaneous water loss occurs with increasing temperature (Bentley and Schmidt-Nielsen, 1966; Schmidt-Nielsen and Bentley, 1966). The data of Dawson et al. (1966) indicate that the relationship between cutaneous water loss (not corrected for saturation deficit changes) and ambient temperature depends upon the species studied. With an increase in air temperature from 20 to $30^{\circ} \mathrm{C}$, the saturation deficit has a $Q_{10}$ of 1.8 ; yet one species of lizard showed no increase in the rate of water loss $\left(Q_{10}=1.0\right.$; Amphibolurus ornatus $)$, one had a $Q_{10}$ of 1.2 , and the rate of water loss of the third species increased at the same rate as the saturation deficit.

In contrast, Roberts (1968) states that air temperature is almost as important a determinant of water loss as is saturation deficit for the lizard Uta stansburiana. Gans et al. (1968) report that flux of THO to water increases with temperature (Elaphe climacophora; $\left.27-34^{\circ} \mathrm{C} ; Q_{10}=2.2\right)$. Flux through excised skin in an osmometer increases with temperature $Q_{10}=1.8$; Tercafs and Schoffeniels, 1965). Thus, the unidirectional flux through the skin can increase in the absence of a change in the vapor pressure deficit.

No single factor explains all these data, but habitat aridity is important. The lizards that show the temperature-independent water loss have a xeric distribution. However, $\underline{\mathbb{U}}$. stansburiana has an increase in cutaneous water loss that is independent of saturation deficit (Roberts, 1968; Clausen, 1967) yet has the same rate of water loss per unit of surface area as $\underline{A}$. ornatus (Dawson et al., 1966) and also occurs in arid habitats. 
The level of cutaneous water loss strongly reflects the species' ecology (Fig. 4). At $25^{\circ} \mathrm{C}$ cutaneous water loss varies from 5.9 per cent of the initial body weight per day in the completely aquatic N. cyclopion, which is 40 per cent of that of an equal-sized amphibian (calculated from Schmid, 1965), to 0.3 per cent per day in the diurnal, desert $\underline{P}$. catenifer. Thamnophis sauritus lost water at the rate of 2.1 per cent per day, reflecting its small size and large weightspecific surface area. The fresh-water N. f. pictiventris loses water at a mean rate of 4.25 per cent per day, while the salt-water N. E. compressicauda has a rate equal to a 1.8 per cent per day. The levels of cutaneous water loss are similar to those previously reported for snakes (Prange and Schmidt-Nielsen, 1969; Chew and Dammann, 1961).

Although water stress is the primary long term determinant of cutaneous permeability, the snake's body posture, feeding state and activity provide short term modifications. However, to understand their effects, some features of reptilian skin must be examined. Squamate skin has an outer and an inner scalar surface, and a hinge region. The most superficial layers of all three parts are keratinized, with B-type (Beta) keratin predominant on the outer scalar surface and A-type (alpha) keratin predominant on the inner scalar surfaces and in the hinge region (Mercer, 1961; from Maderson, 1964, 1965). The A-type keratin is flexible and permits expansion of the skin during breathing, during activity, and after swallowing large prey. Normally the exposed skin surface is the inflexible B-type keratin of the outer scalar surface. If water diffuses through the A-type more rapidly than through B-type keratin, then considerations of water conservation would work against skin distensibility. 
I have two types of evidence indicating that the interscalar surfaces are more permeable than the scalar surfaces. Figure 4 includes data for post-absorptive $\underline{T}$. sauritus, and for the same snake after being fed sufficient fish to spread the scales so that they no longer overlapped and the interscalar surfaces were exposed. A five-fold increase in cutaneous water loss resulted, which was not due to increased activity (oxygen consumption was 1.4 times the post-absorptive rate).

Maximum scale overlap occurs when the snake is straight; overlap is reduced on the outside of curves. Therefore body position should modify cutaneous water loss. Figure 12 illustrates a selected segment of a water loss record with the values plotted as percentage deviations from an arbitrarily chosen baseline (inactive and curved). Water loss decreased when the animal switched from a curved (sinusoidal as distinct from coiled) to a straight position. Tight coiling in an area of low convection would, however, create a shell of high humidity air around the snake and reduce the water loss.

Since cutaneous water loss does not increase with increasing metabolism, the increase in water loss with activity seems to be due to a flushing out of high humidity pockets under the scales (see Gans et al., 1968). In this study, cutaneous water loss increased as much as 3.3 times when the snakes were active. Although in most cases the increase was less than 2 fold.

If overlapping scales are important in reducing water loss for most snakes, then a study of the skin structure of achrochordid snakes would be interesting. These are heterosaline snakes with nonoverlapping scales (Campden-Main, 1970). 


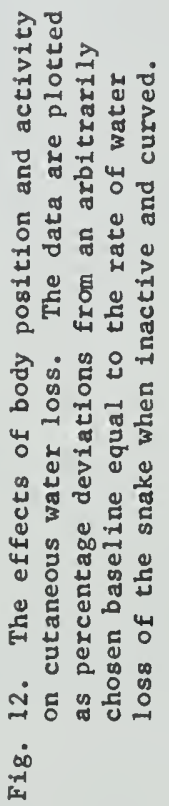




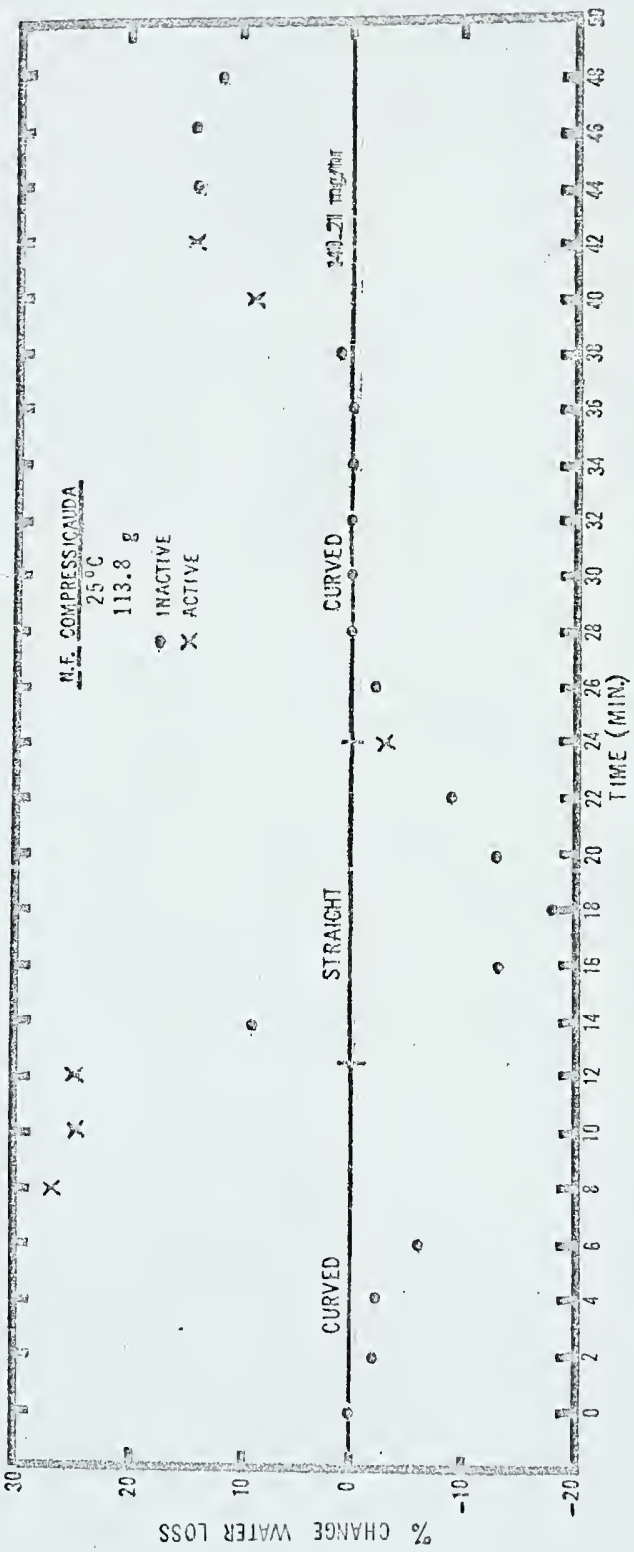


The balance between the need for skin distension and for a reduced cutaneous water exchange deternines the lower limit of cutaneous water loss. High skin permeability may even be advantageous by permitting cutaneous gas exchange (see Crawford and Schultetus, 1970). It appears that the evolutionary determination of this balance point is sensitive to conditions in the environment.

\section{Oxygen Consumption}

Since respiratory water loss depends upon the ventilatory volume, the oxygen consumption was examined (Fig. 5, 6; Table 2). Rates of oxygen consumption are similar to those reported by Galvao et al. (1965) for snakes, and have temperature sensitivities $\left(Q_{10}\right)$ similar to those previously reported for lizards (Dawson, 1967).

Oxygen consumption of the restrained $\underline{N}$. $\underline{f}$. pictiventris was 1.46 times that of equal-sized unrestrained specimens. The maximum increase in oxygen consumption with voluntary activity in the restrained snakes was 7.6. Although in most cases the increase was between 2 and 6 fold.

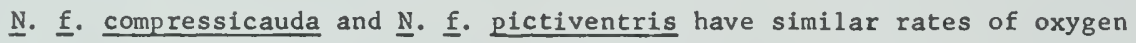
consumption at $25^{\circ} \mathrm{C}$. At 15 and $32^{\circ} \mathrm{C}$ variability of the data and uncertainty about the regression lines prevent statistical separation of the two subspecies (Fig. 7; Table 2).

\section{Respiratory Water Loss}

Just as with oxygen consumption, the rates of respiratory water loss of the two subspecies of $N$. fasciata were equal at $25^{\circ} \mathrm{C}$ (Fig. 10; Table 3). Thamnophis sauritus, which had a lower rate of oxygen consumption than Natrix, also had a lower rate of respiratory water loss. At 15 and $32^{\circ} \mathrm{C}$ there is considerable overlap of respiratory water loss values of the two Natrix subspecies. Statistical separation of the two forms is again not possible. 
The ecologically rationalizable trends of respiratory water loss cited by Bentley and Schmidt-Nielsen (1966) for lizards, turtles, and crocodilians do not emerge from the data on snakes. The respiratory water loss of $\underline{N}$. taxispilota equals that of $\underline{P}$. catenifer (Prange and Schmidt-Nielsen, 1969). However, elevated rates of oxygen consumption in these two species resulted in rates of respiratory water loss that are greater than those reported in Table 3. In the snakes that have been studied the respiratory water loss is mainly a function of oxygen consumption.

The relationship between oxygen consumption and respiratory water loss is not straightforward. Figures 8 and 9 and Table 3 reveal little increase in saturation deficit-independent water loss between 15 and $32^{\circ} \mathrm{C}$, while oxygen consumption showed a $Q_{10}$ in excess of 2.0 throughout the temperature range.

At a common oxygen consumption, the amount of water lost per milliliter of oxygen consumed decreases only slightly with increasing temperature, but at any one temperature except for N. $\underline{\text {. }}$ compressicauda at $15^{\circ} \mathrm{C}$, respiratory water loss increases as a fractional exponential function of oxygen consumption that is independent of activity and body weight (Figs. 13, 14 include both resting and active values. One consequence of having water loss per milliliter of oxygen consumed decrease with increasing oxygen consumption is that respiratory water loss increases with body size and activity less quickly than oxygen consumption (Tables 2,3). Therefore, in terms of water loss, the cost of activity is reduced relative to the change in oxygen consumption. Water loss continues to decrease relative to oxygen consumption and saturation deficit until evaporative cooling is actively increased by panting (Templeton, 1960; Dawson and Templeton, 1963). 
Fig. 13. Water loss per milliliter of oxygen consumed as a function of oxygen consumption in Natrix fasciata pictiventris and Thamnophis sauritus. This graph includes values for inactive and active animals.

Fig. 14. Water loss per milliliter of oxygen consumed as a function of oxygen consumption in Natrix fasciata compressicauda, N. cyclopion and Pituophis catenifer. This graph includes values for inactive and active animals. 

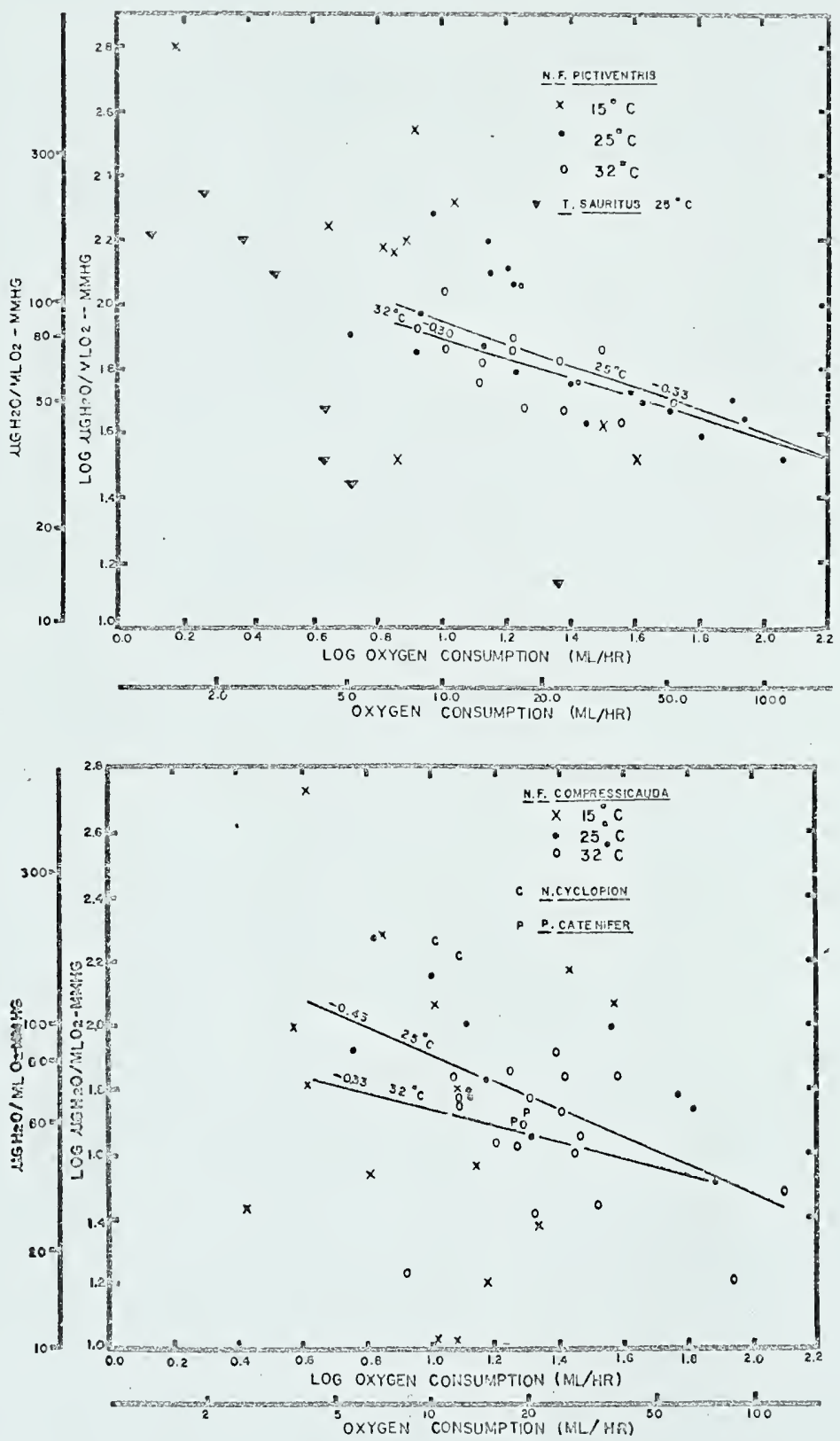
Minute volume and oxygen extraction were exanined to uncover the respiratory mechanisms of the decrease of water loss per milliliter of oxygen consumed at higher rates of metabolism. Minute volume was calculated from the water loss data by dividing the respiratory water loss $(\mathrm{mg} / \mathrm{min})$ by the density of water in saturated air at ambient temperature $(\mathrm{mg} / \mathrm{ml}$; Figs. 15, 16). It was assumed that the exhaled air was at ambient temperature. Oxygen extraction was calculated from the minute volume and oxygen consumption (Dejours, 1966; assuming $R Q=0.7$; Figs. $17,18,19)$.

The savings in respiratory water loss are achleved primarily through the relative reduction in minute volume with increasing oxygen consumption (FLg8, 15, 16). However, at resting metabolic rates, the lack of temperature dependence of ventilation rate (4-8 breaths/min at 25 and $32^{\circ} \mathrm{C}$ ) Indicates that tidal volume is increasing with temperature, and the relative dead space ventilation is decreasing with temperature. This results in further water savings at high temperatures. Unfortunately I have insufficient data on breathing rates to calculate tidal volumes corresponding to each water loss point.

\section{Partitioning of Water Loss}

Within a species, the partitioning of water loss reflects the level of respiratory water loss since cutaneous water loss is temperature independent (Table 4). The respiratory component does not increase greatly with temperature and the partitioning remains within narrow bounds. The changes in partitioning are more complex in lizards since there are species differences in the temperature sensitivity of cutaneous water loss as well as active augmentation of respiratory water loss at higher temperatures. 
Fig. 15. Minute volume as a function of oxygen consumption in Natrix fasciata pictiventris and Thamnophis sauritus. This graph includes values for inactive and active animals.

Fig. 16. Minute volume as a function of oxygen consumption in Natrix fasciata compressicauda. This graph includes values for inactive and active animals. 

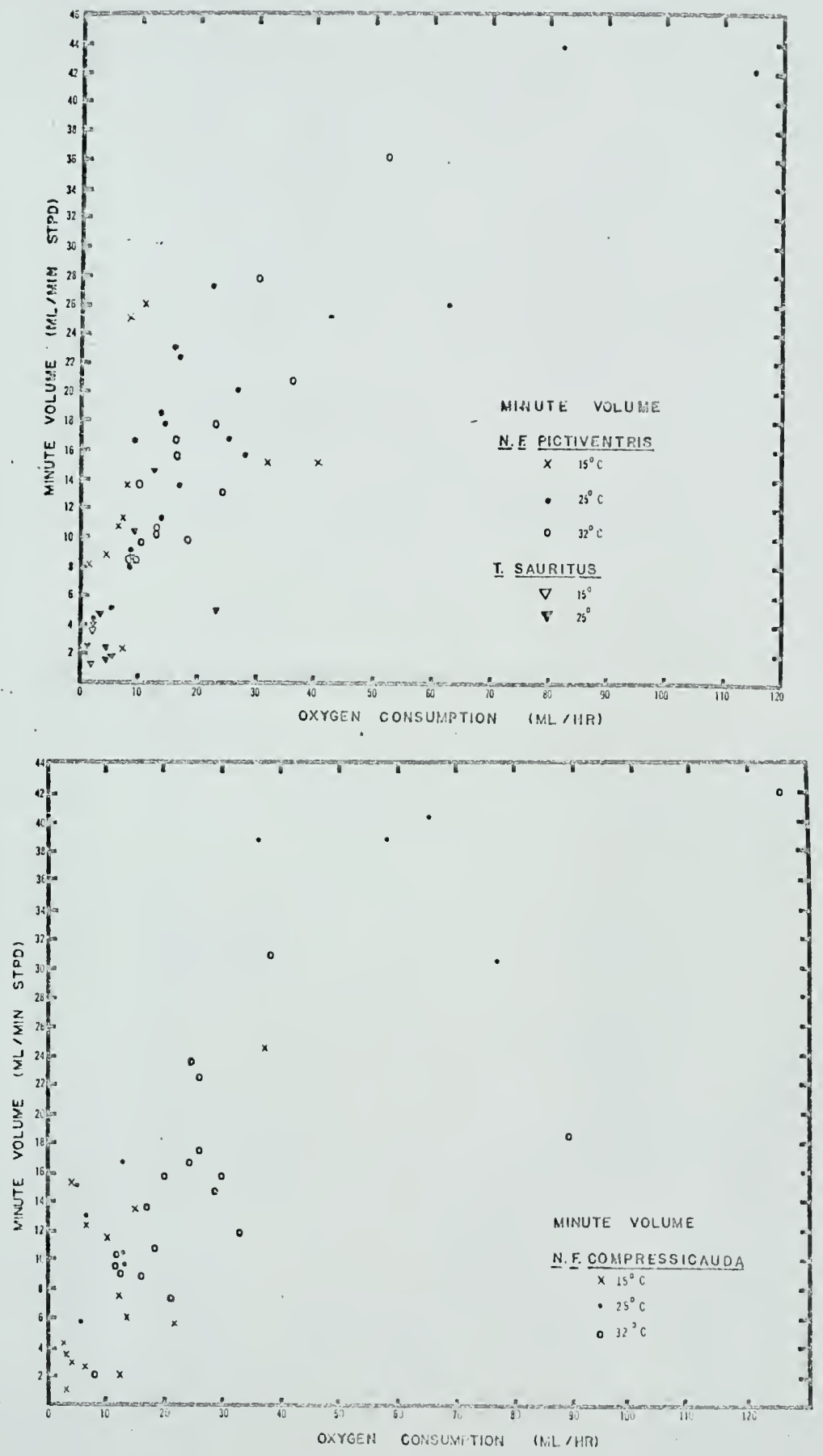

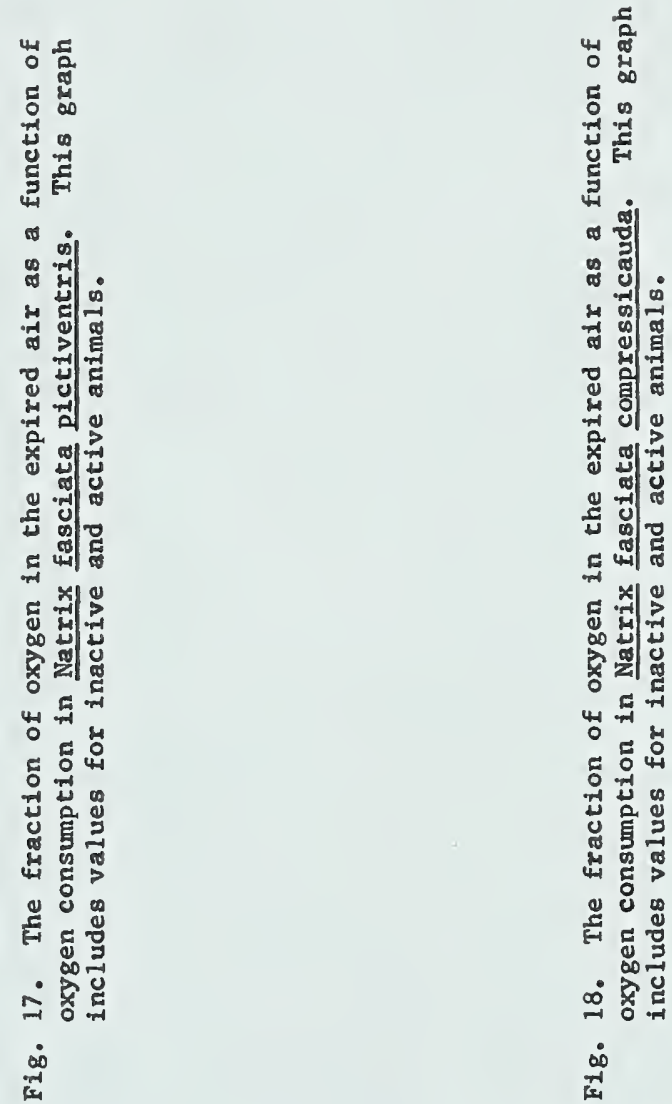


$$
\text { ti }
$$


Fig. 19. The fraction of oxygen in the expired air as a function of oxygen consumption in Thamnophis sauritus. This graph includes values for inactive and active animals. 


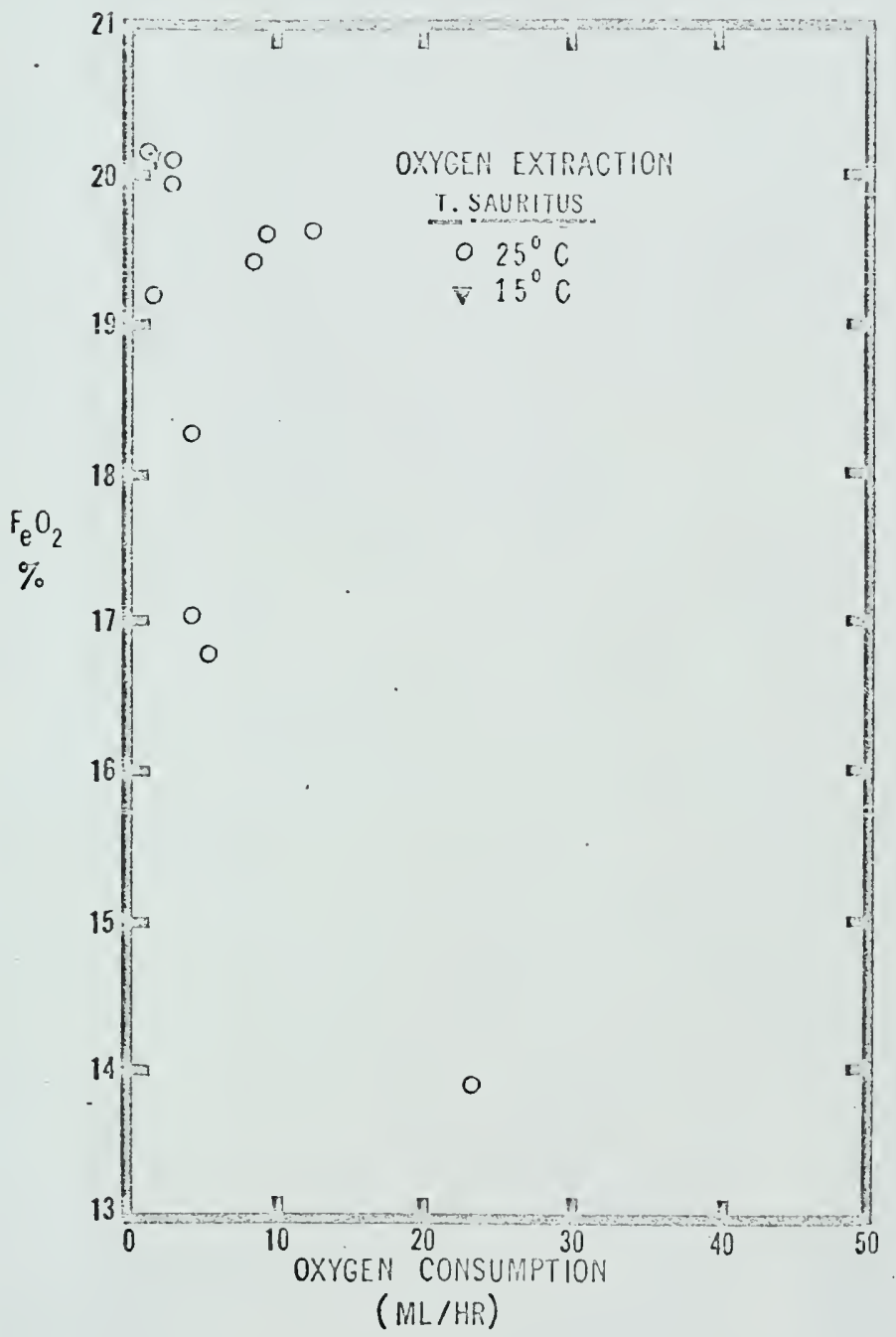


In these snakes, the ecology of the species dictates the differences in partitioning since the magnitude of the cutaneous component is ecologically labile, while the respiratory fraction is dependent upon the organism's demand for oxygen. The level of the basal rate of metabolism is probably also in part a function of the animal's ecology, but is more directly a function of size. The cutaneous fraction of water loss found in this study (72.9-96.8 per cent) is similar to values from the literature for reptiles of comparable ecology (for review, see Schmidt-Nielsen, 1969). The cutaneous fraction of $\underline{N}$. cyclopion is higher than any previously reported.

\section{Water Exchange With Aqueous Media}

Since one finds high skin permeability in air occurring in animals that normally live in or near fresh water and thus are subjected to hydration stress, data on the relative rates of water influx and efflux should be reviewed. The literature is chaotic, with reports of equal permeability in both directions, efflux but no influx, and no flux in either direction.

Tercafs and Schoffeniels (1965) and George (1947) present data on excised reptile skin that indicate equal permeability in both directions. Tercafs and Schoffeniels (1965) also report that certain lizards (but no snakes) gain weight when the animal is in contact with free water. Fluorescein dye placed in the water did not appear in the digestive tract. This was interpreted as indicating influx through the skin.

Capillary flow along the scales to the mouth followed by drinking was shown to be the mechanism of allegedly cutaneous water uptake of the desert lizard Moloch horridus (Bentley and Blumer, 1962). They 
speculate that a similar mechanism is responsible for the other records of apparent water uptake through the skin. Krakauer et al. (1968) report that several burrowing reptiles (snakes and amphisbaenians) that lose water at the same rate as equal-sized amphibians were unable to regain water after dehydration, unless the mouth was able to contact the substrate (moist sand or wet sponge). CloudsleyThompson (1968) made similar observations on Nile crocodiles.

Pettus (1958) reports that no water passes through the excised skin of N. . water subspecies). An osmotic gradient was created across the skin from salt water to distilled water, with either solution in contact with the external skin surface. Presumed death of the skin after 24 hours in the osmometer did not increase the water flux. Pettus' data were the basis of the statement that reptilian water 1088 is primarily respiratory (Chew, 1961).

It is obvious that Pettus' conclusion is erroneous; it may have been due to a high resistance manometer fluid coupled with skin distension that changed the volume in his osmometer compartments. The results that indicate little water influx may reflect natural conditions more closely than those indicating symmetrical skin permeability because they were performed on intact animals.

The isotope experiments in this study (Fig. 11) measure only one-way gross permeability, and do not indicate net flow of liquid. However, since the isotope measurements were made in the presence of an osmotic gradient (body-fresh water, body-salt water), bulk flow along the gradient should interact with the diffusional flow (see Motais et al,, 1969). The isotope flux against the osmotic 
gradient to distilled water is the same as the flux with the gradient to sea water, thus indirectly supporting an hypothesis of a reduced or asymetrical membrane permeability. Unfortunately no reliable measurements of direction and magnitude of net flux were obtained.

Pettus (1963) reports weight loss of around 0.6 per cent per day for $\underline{N}$. $\underline{\text {. clarki }}$ immersed in both distilled and salt water. As is N. f. compressicauda, this is a brackish-water snake that normally relies on the preformed water in its diet to keep in water balance. Therefore, since the snakes were kept without food, and since they do not drink salt water, the rates of weight loss represent the rate of water loss plus the weight loss due to metabolism. The weight loss due to metabolism is probably small. The rate of weight loss in water is lower than the rate of water loss of $N$. f. compressicauda in air ( 1.8 per cent per day) and much lower than the apparent rates from the isotope flux rates ( 9.6 per cent per day; value normalized to the mean weight of the animals used in the dry air runs at $25^{\circ} \mathrm{C}$ ). Since the weight of the animals used in his study was not given, the rates of water loss cannot be rigorously compared.

If the osmotic flow of water is small when the animal is in water, then an explanation must be found for the high diffusion rates through wetted skin observed by Tercafs and Schoffeniels (1965), Gans et al. (1968) and in this study. Tercafs and Schoffeniels (1965) suggest that snakes can regulate permeability depending upon its surroundings, and support this suggestion by pharmacologically modifying water loss rates (atropine and curare increase flux rates across wetted skin). Gans et al. (1968) suggest that hydration of the skin proteins, analogous to the mechanism suggested for insects 
(Beament, 1961), may be responsible for the increase in the diffusion rate across wetted skin. A third possible explanation that is consistent with the data of Gans $\underline{\text { et }}$ al. (1968) and the data presented here concentrates on the difference in magnitude of the scouring forces exerted on the skin under different conditions.

The scouring force is exerted parallel to the skin and determines the width of the immobile she11 around the animal. This force may be calculated by the following equation:

$$
T=C_{f} \rho U^{2}
$$

where $\tau$ is the scouring force in dynes $/ \mathrm{cm}^{2}, C_{f}$ is the coefficient of friction, 0 is the density of the medium, and $U$ equals the velocity of the medium. $C_{f}$ depends upon the roughness of the surface, and the Reynolds number ( $R_{L}$; Sutton, 1953; Knudsen and Katz, 1958).

The Reynolds number is dimensionless and depends upon the velocity of the medium, the length of the flowpath, and the kinematic viscosity (Newtonian viscosity/density). The Reynolds numbers, calculated using the mean water and air flow rates, were in that dubious zone between numbers that indicate laminar or turbulent flow (air 49.1, water 574.2). Laminarity was assumed, allowing $\mathrm{C}_{\mathrm{f}}$ to be calculated from the formula:

$$
\mathrm{C}_{\mathrm{f}}=1.328 /\left(\mathrm{R}_{\mathrm{L}}\right)^{0.5}
$$

The scouring force with water as the external medium will be 21.08 times larger than the force with air as the external medium. The rate of diffusion will depend upon the steepness of the gradient. The more rapidly the scouring of molecules away from the surface of the skin, the steeper the gradient that will be maintained across the skin and thus the greater the flux. 
A ratio of flux rates to water and to air of up to 21 times can be rationalized. The observed ratios were 5.3 for $\underline{N}$. $\underline{\text {. }}$ compressicauda and 11.3 for N. ‥ pictiventris. The increase in diffusion of water to water may just reflect the fluid dynamics of a flowing aquatic medium.

The quantitative meaning of the unidirectional flux measurements is not clear, although these determinations indicate that the brackishwater Natrix has a lower skin permeability in water than does the fresh-water form. Apparently dehydration stress exerts greater selective pressure than does hydration stress. Unfortunately the relationship between water loss and water gain is still not known. 


\section{CONCLUSIONS}

Cutaneous water loss in snakes can be modified by structural means and by behavioral changes in posture and habitat selection. However, the structural means must be compatible with feeding and locomotion, which demands free spreading of the scales (Maderson, 1964), and the behavioral changes must remain consistent with the animal's energetic needs, e.g. activity rhythms are set by the times of prey availability.

Physiologically and ecologically the conclusions appear clear. The brackish-water snake, N. ‥ compressicauda, has reduced skin permeability both in water and on land. This is appropriate for a snake that inhabits saline areas, and lacks accessory salt glands (Schmidt-Nielsen and Fange, 1958).. Its prey are vertebrates, which provide a good source of free water, so it is subject to dehydration stress no more severe than is a desert reptile. The more moderate temperatures of the water snake's habitat decrease the problem of maintaining a water balance. Fresh-water snakes are seldom under dehydration stress, and can benefit from the non-pulmonary gas exchange nomally associated with high water permeability. If there is an increased influx in fresh water associated with the higher skin permeability of aquatic snakes, then the kidneys must get rid of the added water load.

Respiratory water loss can be changed by behavioral or by anatomical and physiological modifications. Respiratory water loss depends upon the total pulmonary ventilation, the humidity of the 
inspired air, and the temperature of the expired air (since it is saturated with water vapor). It can be reduced by reducing the oxygen consumption to decrease the ventilation volume. But the level of the basal rate of metabolism is determined by the homeostatic demands of the organism. Apparently N. f. pictiventris and $\underline{N}$. $\underline{\text {. }}$ compressicauda are similar enough that in spite of differences in the water stress of the environment, water conservation cannot be achieved by reducing the rate of metabolism. T. sauritus has a reduced respiratory water loss that corresponds to its lowered rate of metabolism.

Since respiratory water loss at rest is only a small fraction of the total water loss, it appears that the most significant adaptations are not those that decrease the resting rate, but are those that decrease the rate of increase with activity. Ventilation volume is reduced by an increase in oxygen extraction at higher rates of metabolism. This results in water savings, but requires changes in the acid-base balance and respiratory characteristics of the blood. Reduction of the relative dead-space ventilation by increasing tidal volume also serves to decrease the ventilation volume corresponding to a given rate of metabolism. 


\section{SUMMARY}

The ecological and physiological control of water loss was studied in closely related but ecologically distinct snakes. The main conclusions are:

1. Cutaneous water loss measured in dry moving air does not increase with increasing temperature when the water loss is expressed as a function of the vapor pressure deficit.

2. Cutaneous water loss correlates with the water availability in the natural environment of each of the species and varies from 5.9 per cent of the initial body weight per day for the wholly aquatic Natrix cyclopion to 0.3 per cent per day for the desert snake Pituophis catenifer. The fresh-water N. fasciata pictiventris had a higher skin permeability ( 4.25 per cent per day) than the brackish water $\underline{N}$. $\underline{\text {. }}$ compressicauda ( 1.8 per cent per day).

3. In the interscalar regions of the skin permeability is higher than in the scalar regions, resulting in changes in cutaneous water loss with changes in posture, activity and feeding state.

4. Rates of respiratory water loss are not ecologically rationalizable, but rather depend upon the level of oxygen consumption.

5. Respiratory water loss when expressed as a function of oxygen consumption and saturation deficit increases as a fractional power of oxygen consumption. Respiratory water loss therefore increases less rapidly with activity than does oxygen consumption. 
6. Cutaneous water loss contributes between 72 and 97 per cent of the total water loss. With the rate of respiratory water loss fixed by the level of oxygen consumption, the differences in water loss partitioning are due to the ecologically rationalizable differences in cutaneous water 1oss.

7. Skin permeability measured in aqueous media is greater in $\underline{N}$. $\underline{f}$. pictiventris than in N. f. compressicauda. 


\section{REFERENCES}

Beament J. W. L. (1961) The water relations of insect cuticle. Biol. Rev. 36, 281-320.

Bentley P. J. (1959) Studies on the water and electrolyte metabolism of the lizard Trachysaurus rugosus. J. Physiol. 145, 37-47.

Bentley P. J. and Blumer W. F. C. (1962) Uptake of water by the lizard Moloch horridus. Nature 194, 699-700.

Bentley P. J. and Schmidt-Nielsen K. (1966) Cutaneous water loss in reptiles. Science 151, 1547-1549.

Bogert C. and Cowles R. (1947) Results of the Archbold expedition, No. 58. Moisture loss in relation to habitat selection in some Floridian reptiles. Amer. Mus. Novitates 1358, 1-34.

Campden-Main S. M. (1970) A field guide to the snakes of South Vietnam, Division of Reptiles and Amphibians. U. S. Nat1. Mus. Smithsonian Inst., Washington. 1-114.

Chew R. M. (1961) Water metabolism of desert inhabiting vertebrates. Biol. Rev. 36, 1-31.

Chew R. M. and Dammann A. E. (1961) Evaporative water loss of small vertebrates, as measured with an infrared analyser. Science 133, 384-385.

Clausen D. L. (1967) Studies of water loss in two species of lizards. Comp. Biochem. Physio1. 20, 115-130.

Cloudsley-Thompson J. L. (1968) Water relations of crocodiles. Nature $\underline{20}$ (5168), 708 .

Crawford E. C., Jr. and Schultetus R. R. (1970) Cutaneous gas exchange in the lizard Sauromalus obesus. Copeia 1970, 179-180.

Dawson W. R. (1967) Interspecific variation in physiological response of lizards to temperature. 230-257. In W. W. Milstead (ed) Lizard Ecology: A Symposium. Univ. Missouri Press, Columbia.

Dawson W. R., Shoemaker V. H. and Licht P. (1966) Evaporative water losses of some small Australian lizards. Ecology 47, 589-594.

Dawson W. R. and Templeton J. R. (1963) Physiological responses to temperature in the lizard Crotaphytus collaris. Physiol. Zool. 36, 219-236. 
Dejours P. (1966) Respiration. Oxford Univ. Press, New York.

Galvao P. E., Tarasantchi J. and Guertzenstein P. (1965) Heat production of tropical snakes in relationship to body weight and body surface. Am. J. Physiol. 209, 501-506.

Gans C., Krakauer T. and Paganelli C. V. (1968) Water loss in snakes: Interspecific and intraspecific variability. Comp. Biochem. Physiol. 27, 747-761.

George J. C. (1947) A comparative study of permeability to water of the skin in some representative vertebrates. J. Univ. Bombay 16, 28-32.

Knudsen J. G. and Katz D. L. (1958) Fluid Dynamics and Heat Fransfer. McGraw-Hi 11 Book Co., New York.

Krakauer T., Gans C. and Paganelli C. V. (1968) Ecological correlation of water loss in burrowing reptiles. Nature 218 (5142), 659-660.

Maderson P. F. A. (1964) The skin of lizards and snakes. Brit. J. Herpetology $3,151-154$.

Maderson P. F. A. (1965) Histological changes in the epidermis of snakes during the sloughing cycle. J. Zool. 146, 98-113.

Mercer E. H. (1961) Keratin and Keratinization. Pergamon, London.

Motais R., Isaia J., Rankin J. C. and Maetz J. (1969) Adaptive changes of the water permeability of the teleostean gill epithelium in relation to external salinity. J. Exp. Biol. 51, 529-546.

Pettus D. (1958) Water relations in Natrix sipedon. Copeia 1958, 207-211.

Pettus D. (1963) Salinity and subspeciation in Natrix sipedon. Copeia 1963, 499-504.

Prange H. D. and Schmidt-Nielsen K. (1969) Evaporative water loss in snakes. Comp. Biochem. Physiol. 28, 973-975.

Roberts L. A. (1968) Water loss in the desert lizard Uta stansburiana. Comp. Biochem. Physio1. 27, 583-589.

Schmid W. D. (1965) Some aspects of the water economies of nine species of amphibians. Ecology 46, 26I-269.

Schmidt-Nielsen K. (1969) The neglected interface: The biology of water as a liquid-gas system. Quart. Rev. Biophys. 2, 283-304.

Schmidt-Nielsen K. and Bentley P. J. (1966) Desert tortoise Gopherus agassazil: Cutaneous water 1oss. Science 154, 911.

Schmidt-Nielsen K. and Fange R. (1958) Salt glands in marine reptiles. Nature $182,783-785$. 
Sutton 0. G. (1953) Micrometerology. McGraw-Hil1 Book Co., New York.

Tabb D. C., Dubrow D. L. and Manning R. B. (1962) The ecology of northern Florida Bay and adjacent estuaries. State of Florida, Board of Conservation Tech. Ser. No. 39.

Templeton J. R. (1960) Respiration and water loss at higher temperatures in the desert igauna, Dipsosaurus dorsalis. Physiol. Zool. 33, 136-145.

Tercafs P. R. and Schoffeniels E. (1965) Phenomenés de perméabilité au niveau de 1 a peau des reptiles. Ann. Roy. Soc. Zool. Belgium 96, 9-22.

Thorson T. B. (1968) Body fluid partitioning in reptilia. Copeia 1968, 592-601. 


\section{BIOGRAPHICAL SKETCH}

Thomas Henry Krakauer was born September 6, 1942, at Buffalo, New York. In June, 1959, he was graduated from The Park School of Buffalo. In June, 1964, he received the degree of Bachelor of Arts with a major in Biology from the University of Rochester. In June, 1966, he received the degree of Master of Science with a major in Biology from the University of Miami. In 1966 he enrolled in the Graduate School of the University of Florida. He worked as an Interim Instructor in the Department of Zoology until June, 1967. His work toward the degree of Doctor of Philosophy was further supported by a National Defense Education Act, Title IV Fellowship and a University of Florida Graduate School Fellowship.

Thomas Henry Krakauer is married to the former Janet MacColl. 
This dissertation was prepared under the direction of the chairman of the candidate's supervisory committee and has been approved by all members of that committee. It was submitted to the Dean of the College of Arts and Sciences and to the Graduate Council, and was approved as partial fulfillment of the requirements for the degree of Doctor of Philosophy. August, 1970.

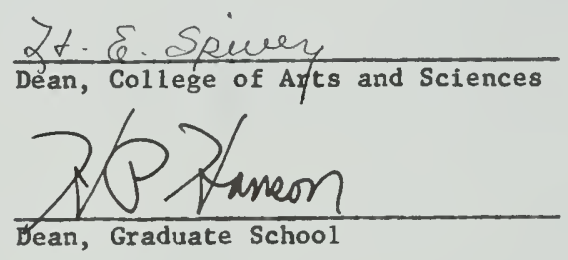

Supervisory Committee:

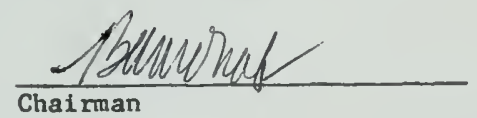

I tamil A Belkin

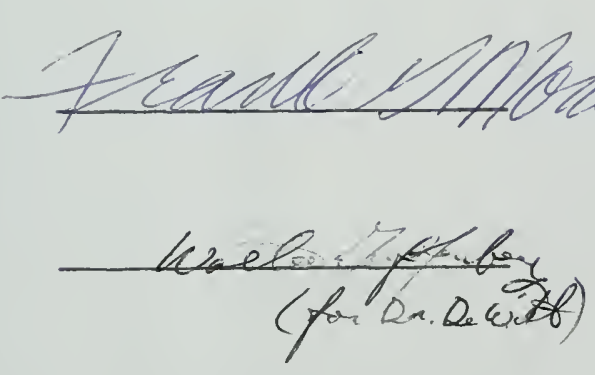


\#59 Loe mam 138(100

3. 106.89 